\title{
Potential of the tumor-derived extracellular vesicles carrying the miR-125b-5p target TNFAIP3 in reducing the sensitivity of diffuse large $B$ cell lymphoma to rituximab
}

\author{
LI ZHANG ${ }^{1-3}$, SHIXIA ZHOU ${ }^{4,5}$, TIEJUN ZHOU ${ }^{6},{\text { XIAOMING } \mathrm{LI}^{4,5} \text { and JUNLING TANG }}^{4,5}$ \\ ${ }^{1}$ Department of Oral and Maxillofacial Surgery, The Affiliated Stomatology Hospital of Southwest Medical University; \\ ${ }^{2}$ Orofacial Reconstruction and Regeneration Laboratory, The Affiliated Stomatology Hospital of \\ Southwest Medical University; ${ }^{3}$ Department of Oral and Maxillofacial Surgery, The Affiliated Hospital of \\ Southwest Medical University; ${ }^{4}$ Department of Hematology, The Affiliated Hospital of Southwest Medical University; \\ ${ }^{5}$ Stem Cell Laboratory, The Affiliated Hospital of Southwest Medical University; ${ }^{6}$ Department of Pathology, \\ The Affiliated Hospital of Southwest Medical University, Luzhou, Sichuan 646000, P.R. China
}

Received September 27, 2020; Accepted March 1, 2021

DOI: $10.3892 /$ ijo.2021.5211

\begin{abstract}
Diffuse large B-cell lymphoma (DLBCL) is the most common and aggressive form of non-Hodgkin's lymphoma. Extracellular vesicles (EVs) derived from cancer cells are known to modify the tumor microenvironment. The aim of the present study was to investigate the role of miR-125b-3p carried by EVs in DLBCL in vitro and in vivo. TNFAIP3 expression in patient lesions was measured and the upstream miR that regulates TNFAIP3 was predicted using the starBase database. EVs were isolated from DLBCL cells and identified. DLBCL cells were transfected with pcDNA to overexpress TNFAIP3 or inhibit miR-125b-5p expression, incubated with EVs, and treated with rituximab to compare cell growth and TNFAIP3/CD20 expression. DLBCL model mice were administered EVs, conditioned medium, and rituximab to observe changes in tumor size, volume, and weight. TNFAIP3 was downregulated in patients with DLBCL and its levels further decreased in patients with drug-resistant DLBCL. Overexpression of TNFAIP3 in DLBCL cells enhanced the inhibitory effect of rituximab and increased CD20 expression. miR-125b-5p targeted TNFAIP3. Inhibition of miR-125b-5p enhanced the inhibitory effect of rituximab in DLBCL cells. The EV-carried miR-125b-5p reduced the sensitivity of DLBCL cells to rituximab, which was averted by overexpression of TNFAIP3. EVs reduced the sensitivity of DLBCL model mice to rituximab via the miR-125b-5p/TNFAIP3 axis. The study findings indicate that the tumor-derived EVs carrying
\end{abstract}

Correspondence to: Dr Junling Tang, Department of Hematology, The Affiliated Hospital of Southwest Medical University, No. 25 Tai Ping Street, Luzhou, Sichuan 646000, P.R. China

E-mail: polycloneRES_TJL@swmu.edu.cn

Key words: diffuse large B-cell lymphoma, extracellular vesicles, microRNA-125b-5p, TNFAIP3, rituximab, sensitivity
miR-125b-5p can enter DLBCL cells and target TNFAIP3, thus reducing the sensitivity of DLBCL to rituximab, which may provide a novel therapeutic approach for DLBCL.

\section{Introduction}

Diffuse large B-cell lymphoma (DLBCL) is the most common aggressive pediatric mature B-cell non-Hodgkin's lymphoma (NHL), with a high incidence of short- and long-term toxicity after chemotherapy regimens (1). It is also common in older adults, comprising $60 \%$ of all lymphoid malignancies in this population (2). DLBCL is characterized by an infiltration of medium to large cells with large nucleoli and ample cytoplasm, which disturbs the basic structure of the affected lymph node (3). The disease is invasive and patients usually show rapid lymph node enlargement and physical symptoms, requiring immediate treatment (3). Rituximab, a monoclonal antibody against CD20, has improved the survival of high-risk patients and reduced the requirement of total chemotherapy for low-risk patients (1). Although most patients receiving rituximab achieve complete remission, approximately $30 \%$ of patients relapse or fail to achieve event-free survival within 24 months after diagnosis, with a median survival time of approximately 10 months (4). In such cases, promising approaches are imperative to counter rituximab resistance.

Tumor necrosis factor necrosis factor alpha-induced protein 3 (TNFAIP3), also known as A20, is a negative regulator of nuclear factor kappa B $(\mathrm{NF}-\kappa \mathrm{B})$ that has been implicated as a tumor suppressor in multiple types of B-cell lymphoma (5). In mice, B-cell specific deletion of TNFAIP3 enhances B-cell proliferation and autoantibody production, while the germline inactivation of TNFAIP3 results in early lethality due to inflammation in multiple organs (6). TNFAIP3 genetic alterations are involved in DLBCL pathogenesis (7). In a previous study, the negative prognostic significance of TNFAIP3 deletion and somatic mutation was reported in gastrointestinal DLBCL (8). Notably, TNFAIP3 deletion is marginally associated with a favorable prognosis in rituximab-treated 
populations (9). However, the mechanism of TNFAIP3 in the sensitivity of DLBCL to rituximab is largely unknown.

Extracellular vesicles (EVs), nanometer-sized, cell-secreted membrane vesicles, are critical to intercellular communication between tumor cells and resident cells (10). In particular, EVs obtained from cancer cells are known to modify the tumor microenvironment and promote tumor progression (11). Of note, DLBCL-derived EVs can regulate macrophage polarization and thus contribute to tumor progression (12). MicroRNAs (miRs), a cargo of EVs, are also essential for DLBCL development (13). Aberrant expression of miRs has been shown to have a profound impact on treatment outcomes and chemoresistance in DLBCL (14). Therefore, it was hypothesized that TNFAIP3 may be regulated by a miR shuttled in DLBCL cell-derived EVs, thus modulating the sensitivity of DLBCL to rituximab. In the present study, the possible mechanism of TNFAIP3 targeted by the EV-carried miRs in DLBCL was explored to offer a novel theoretical basis for the management of DLBCL.

\section{Materials and methods}

Ethics statement. The study obtained approval from the Ethics Committee of The Affiliated Hospital of Southwest Medical University (China; no. 20180306006). The clinical registration number is KY2019091. Animal experiments were implemented on the guide for the care and use of laboratory animals, and approved by the Ethics Committee of The Affiliated Hospital of Southwest Medical University (animal ethics no. 20180306006; human ethics no. KY2019091).

Patients. A total of 34 patients with DLBCL, who underwent surgical resection at The Affiliated Hospital of Southwest Medical University from August 2017 to August 2019, were selected as the DLBCL group, including 20 males and 14 females, aged 38-64 years. The inclusion criteria were as follows: i) Patients diagnosed with DLBCL by pathology; ii) patients conforming to surgical indications; iii) patients who did not receive chemotherapy prior to surgery; iv) patients with complete clinical and pathological data and signed informed consent. Patients with other hematological or solid malignancies, liver and kidney dysfunction, autoimmune diseases, or infectious diseases were excluded. Furthermore, 30 patients with DLBCL without remission after 6 cycles of rituximab treatment were selected as the DLBCL-R group, including 18 males and 12 females, aged 32-64 years. At the same time, another 35 patients with reactive hyperplasia of lymph nodes, confirmed by pathology at The Affiliated Hospital of Southwest Medical University, were selected as the control group, including 23 males and 12 females, aged 34-68 years. There was no significant difference in the general data among the three groups (Table I, P>0.05).

Cell culture. DLBCL cell lines SUDHL-4 (SUD, GCB subtype), OCI-LY8 (LY8, GCB subtype), and NU-DUL-1 (DUL, ABC subtype) and 293T cells were purchased from the American Type Culture Collection (ATCC). LY8 cells were cultured in Iscove modified Dulbecco's medium (HyClone) containing $10 \%$ fetal bovine serum (FBS; Gibco) and $1 \%$ penicillin/streptomycin. SUD and DUL cells and 293T cells were cultured in RPMI-1640 medium, containing 10\% FBS and $1 \%$ penicillin/streptomycin (HyClone), at $37^{\circ} \mathrm{C}$ under $5 \% \mathrm{CO}_{2}$. When necessary, $1 \%$ antibiotics (penicillin, streptomycin, amphotericin) (Gibco) were added to the medium to maintain the culture. Cells were passaged every 2-3 days.

Isolation and identification of EVs. SUD cells were cultured in DMEM or RPMI-1640 medium with 10\% EV-depleted FBS and $1 \%$ penicillin/streptomycin for $48 \mathrm{~h}$. The supernatant was centrifuged at $100 \mathrm{x}$ g for $5 \mathrm{~min}$ to remove cells and cellular debris, and then centrifuged at $3,600 \times \mathrm{g}$ and $4^{\circ} \mathrm{C}$ for $30 \mathrm{~min}$ to remove large vesicles. The supernatant was then filtered through a $0.2 \mu \mathrm{m}$ filtration membrane (Millipore), followed by centrifugation at $100,000 \mathrm{xg}$ and $4^{\circ} \mathrm{C}$ for $2 \mathrm{~h}$. The EVs were washed with PBS and centrifuged again at 100,000 $\mathrm{x} g$ and $4^{\circ} \mathrm{C}$ for $2 \mathrm{~h}$. Finally, EVs were suspended in PBS. Similarly, GW4869 (20 $\mu \mathrm{g} / \mathrm{ml}$ conditioned medium; Sigma-Aldrich) was added to EV-depleted FBS, in which SUD cells were cultured for $48 \mathrm{~h}$. The conditioned medium was then used as a control (GW4896 group). The concentration of EV protein, detected using the Bicinchoninic Acid Protein Assay Kit (Thermo Fisher Scientific), was $1.5 \mathrm{mg} / \mathrm{ml}$. The expression levels of CD9 (ab92726), TSG101 (ab125011), and calnexin (ab22595) (all from Abcam) were detected using western blot analysis. EV morphology was observed with transmission electron microscopy (TEM), and EV particle size was detected using a nanoparticle tracking analyzer (NTA) (Malvern Panalytical Co., Ltd.).

PHK-26 labeling for EV location. EV particles were resuspended in $1 \mathrm{ml}$ diluent C. PKH-26 (2 $\mu 1$ mixed with $245 \mu 1$ diluent C; Sigma-Aldrich) was added to the EV suspension for $5 \mathrm{~min}$, followed by the addition of $1 \%$ bovine serum albumin to terminate the labeling reaction. Subsequently, LY8 or DUL cells were seeded in 24-well plates and PKH-26-labeled EVs $(10 \mu \mathrm{g})$ were added to each well. After fixing the cells with $4 \%$ formaldehyde for $24 \mathrm{~h}, 4$ ',6-diamidino-2-phenylindole (DAPI; Sigma-Aldrich) was used for nucleus staining. Finally, the DLBCL cells were observed for EV internalization, using laser scanning confocal microscopy (LSM710, Zeiss).

Cell transfection. According to the manufacturer's instructions, miR-125b-5p inhibitor and its negative control (NC) $(50 \mathrm{nM}$, GenePharma Co., Ltd.), pcDNA-TNFAIP3, and pcDNA-NC (40 nM, Sangon Biotech Co., Ltd.) vectors were transfected into LY8 or DUL cells using Lipofectamine ${ }^{\mathrm{TM}} 2000$ (Thermo Fisher Scientific) according to the manufacturer's instructions. The DLBCL cells were then incubated with the conditioned medium from SUD cells treated with $30 \mu \mathrm{g}$ EVs or GW4869 for $24 \mathrm{~h}$ at $37^{\circ} \mathrm{C}$.

miR-125b-5p inhibitor and its NC were transfected into SUD cells using Lipofectamine ${ }^{\mathrm{TM}} 2000$, followed by incubation for $4 \mathrm{~h}$ at $37^{\circ} \mathrm{C}$. The cells were cultured in complete medium for $48 \mathrm{~h}$, and then EVs were isolated and incubated with LY8 and DUL cells.

3-(4,5-Dimethylthiazol-2-yl)-2,5-diphenyltetrazolium bromide (MTT) assay. Cells in the logarithmic phase were collected and treated with rituximab $(2.5,5,10,20$, and $40 \mu \mathrm{g} / \mathrm{ml})(15)$, and the cell suspension concentration was adjusted to $1 \times 10^{5}$ cells $/ \mathrm{ml}$. 
Table I. Clinical characteristic of DLBCL patients.

\begin{tabular}{|c|c|c|c|c|c|}
\hline Characteristics & Control $(\mathrm{N}=35)$ & $\operatorname{DLBCL}(\mathrm{N}=34)$ & DLBCL+R $(\mathrm{N}=30)$ & $\chi^{2} / \mathrm{F}$ & P-value \\
\hline $\mathrm{Age}^{\mathrm{a}}$ & $34-68($ mean $=49.74)$ & $38-64($ mean=49.03 $)$ & $32-64($ mean $=45.30)$ & 2.622 & 0.078 \\
\hline Male & $23 / 35$ & $20 / 34$ & $18 / 30$ & 0.394 & 0.821 \\
\hline \multicolumn{6}{|l|}{ Pathology type } \\
\hline GCB & 1 & $15 / 34$ & $13 / 30$ & 0.345 & 0.842 \\
\hline $\mathrm{ABC}$ & 1 & $14 / 34$ & $11 / 30$ & & \\
\hline Unknown & 1 & $5 / 34$ & $6 / 30$ & & \\
\hline \multicolumn{6}{|c|}{ Performance status (ECOG) } \\
\hline $0-1$ & $28 / 35$ & $29 / 34$ & $26 / 30$ & 0.611 & 0.737 \\
\hline 2 & $7 / 35$ & $5 / 34$ & $4 / 30$ & & \\
\hline \multicolumn{6}{|c|}{ Lactic dehydrogenase } \\
\hline Normal & $23 / 35$ & $20 / 34$ & $19 / 30$ & 0.359 & 0.836 \\
\hline Elevated & $12 / 35$ & $14 / 34$ & $11 / 30$ & & \\
\hline Ann Arbor stage & & & & 0.779 & 0.446 \\
\hline I-II & 1 & $19 / 34$ & $20 / 30$ & & \\
\hline III-IV & 1 & $15 / 34$ & $10 / 30$ & & \\
\hline
\end{tabular}

DLBCL, diffuse large B-cell lymphomas; DLBCL+R, diffuse large B-cell lymphomas + resistance (resistance to rituximab); GCB, germinal

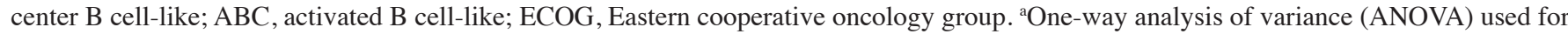
comparison among multiple groups followed by Tukey's multiple comparisons test, or Chi square test used to compare the data.

The cells were seeded in 96 -well plates $(100 \mu 1 /$ well $)$ at $37^{\circ} \mathrm{C}$ under $5 \% \mathrm{CO}_{2}$ for $48 \mathrm{~h}$ and observed using an inverted microscope (Leica).

Subsequently, $10 \mu \mathrm{l}$ MTT (5 mg/ml, Sigma-Aldrich) was added to each well for $4 \mathrm{~h}$. Following centrifugation at $400 \mathrm{x} \mathrm{g}$ and $4^{\circ} \mathrm{C}$ for $15 \mathrm{~min}, 200 \mu \mathrm{l}$ dimethyl sulfoxide was added to each well and plates were placed in a decolorizing shaker for $20 \mathrm{~min}$ to fully dissolve the crystal. Optical density (OD) at $570 \mathrm{~nm}$ was measured using a microplate reader (Bio-Rad Laboratories).

Cell apoptosis. Cell apoptosis was detected using the PE Annexin V Apoptosis Detection Kit with 7-aminoactinomycin D, according to the manufacturer's instructions (BD Bioscience). The number of apoptotic cells was quantified using the BD FACSCalibur flow cytometer system (BD Bioscience) and CellQuest Pro software (BD Bioscience).

Dual-luciferase reporter gene assay. The TNFAIP3 3'UTR fragment containing the miR-125b-5p binding site (WT) and the fragment containing the site-directed mutagenesis modification site (MUT) were cloned into psiCHECK-2.0 vector (Promega). Then, the $293 \mathrm{~T}$ cells (ATCC) treated with miR-125b-5p mimic or miR-125b-5p mimic NC (RiboBio) were co-transfected with WT or MUT plasmids, with phRL-tk transfection (Renilla luciferase) as positive control. After $48 \mathrm{~h}$ of transfection, luciferase activity was detected using a luciferase reporter kit (E1910, Think-Far Technology Co., Ltd, Beijing, China). Luciferase intensity was expressed in relative luciferase units (percentage relative to the control group).

Reverse transcription-quantitative polymerase chain reaction (RT-qPCR). The RNAiso plus kit (Takara, Dalian, China) was used to extract total RNA from SUD, LY8, and DUL cells, EVs, and tissues. The total RNA was reverse transcribed into cDNA using PrimeScript RT reagent kit (Takara). RT-qPCR was performed on a 7500 Real-Time PCR system using the SYBR-Green PCR kit (Takara Bio). The reaction conditions were pre-denaturation at $95^{\circ} \mathrm{C}$ for $10 \mathrm{~min}$, denaturation at $95^{\circ} \mathrm{C}$ for $10 \mathrm{sec}$, annealing at $60^{\circ} \mathrm{C}$ for $20 \mathrm{sec}$, and extension at $72^{\circ} \mathrm{C}$ for $34 \mathrm{sec}$, a total of 40 cycles. U6 or GAPDH served as the internal reference. Quantitative expression was calculated using the $2^{-\Delta \Delta \mathrm{CT}}$ method (16). The primers used are shown in Table II.

Western blot analysis. Patient focus or mouse tumor tissue homogenate or cells were lysed in RIPA buffer containing $50 \mathrm{mM}$ Tris- $\mathrm{HCl}$ ( $\mathrm{pH} 7.5$ ), $150 \mathrm{mM} \mathrm{NaCl}, 1 \% \mathrm{NP}-40$, $0.1 \%$ SDS, $0.5 \%$ sodium deoxycholate, $5 \mathrm{mM}$ EDTA, $0.1 \mathrm{mM}$ $\mathrm{PMSF}$, and $2 \mathrm{mg} / \mathrm{ml}$ aprotinin. Protein concentration was measured using the BCA kit (Beijing Solarbio Science \& Technology Co., Ltd.). Then, the proteins (50 $\mu \mathrm{g} /$ lane) were separated with $10 \%$ sodium dodecyl sulfate polyacrylamide gel electrophoresis (Beyotime Biotech) and transferred onto nitrocellulose membranes. The membranes were blocked with $3 \%$ blocking buffer (Beyotime) for $1 \mathrm{~h}$ at room temperature and cultured with the primary antibodies TNFAIP3 $(1: 1,000$, ab92324, Abcam) and CD20 (1:1,000, Abcam) overnight at $4^{\circ} \mathrm{C}$. Subsequently, the membranes were cultured with the secondary antibody horseradish peroxidase-conjugated goat anti-rabbit IgG (1:5,000, ab205718, Abcam) for $2 \mathrm{~h}$. Next, the membranes were visualized using an enhanced chemiluminescence reagent (Millipore). Protein blotting was analyzed using the Image Pro Plus 6.0 software (National Institutes of Health), with $\beta$-actin as the internal reference. The experiment was repeated three times. 
Table II. Primer sequences for RT-qPCR.

\begin{tabular}{|c|c|c|}
\hline Primer & Sequences $\left(5^{\prime}-3^{\prime}\right)$ & Accession \\
\hline \multirow[t]{2}{*}{ TNFAIP3 } & F: ATGGCTGAACAAGTCCTTCCTCAG & NM_001270507 \\
\hline & R: TTAGCCATACATCTGCTTGAACTGA & \\
\hline \multirow[t]{2}{*}{$C D 20$} & F: ATGACAACACCCAGAAATTCAGTA & NM_021950 \\
\hline & R: TTAAGGAGAGCTGTCATTTTCTAT & \\
\hline \multirow[t]{2}{*}{$m i R-125 b-5 p$} & F: TCCCTGAGACCCTAACTTGTGA & MIMAT0000423 \\
\hline & R: TCACAAGTTAGGGTCTCAGGGA & \\
\hline \multirow[t]{2}{*}{ U6 } & F: CGCTTCGGCAGCACATATAC & NR_004394 \\
\hline & R: AATATGGAACGCTTCACGA & \\
\hline \multirow[t]{2}{*}{$G A P D H$} & F: ATGGTTTACATGTTCCAATATGA & NM_001256799 \\
\hline & R: TTACTCCTTGGAGGCCATGTGG & \\
\hline
\end{tabular}
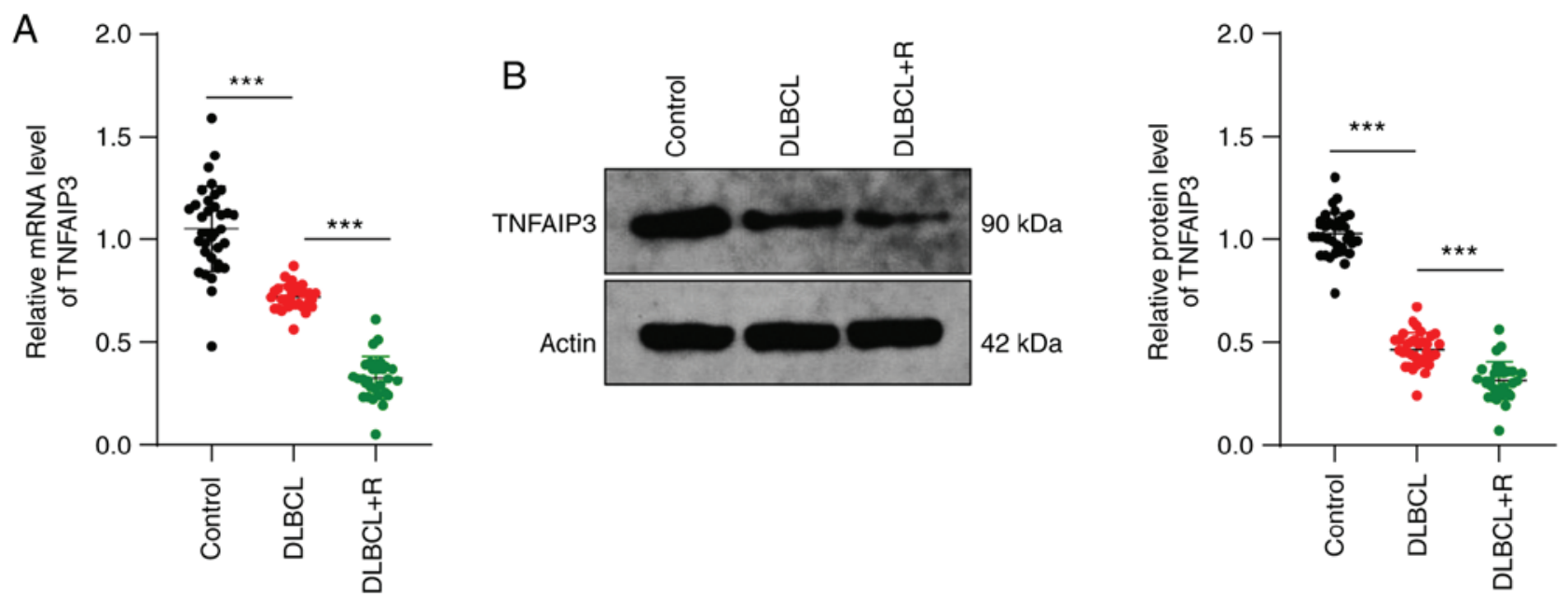

Figure 1. TNFAIP3 is poorly expressed in DLBCL. (A and B) TNFAIP3 mRNA and protein levels in tissues analyzed with RT-qPCR and western blotting ( $\mathrm{n}=35$ Controls, 34 DLBCL, 30 DLBCL-R). One-way ANOVA was used for comparisons among multiple groups, followed by Tukey's multiple comparisons test. ${ }^{* * *} \mathrm{P}<0.001$. DLBCL, patients with diffuse large B-cell lymphoma; DLBCL-R; patients with DLBCL without remission after six cycles of rituximab treatment; Control, patients with reactive hyperplasia of lymph nodes.

Establishment of a mouse model of DLBCL. Female nude mice (5-6 weeks old) were purchased from the Shanghai Experimental Animal Center and raised under aseptic laminar flow conditions. The mice were reared at 50-60\% humidity and $25^{\circ} \mathrm{C}$, and maintained in a $12 \mathrm{~h}$ light/dark cycle. Food and water were provided a Extracellular vesicles d libitum.

Each mouse was injected with $2 \times 10^{7}$ LY8 cells into the right abdomen. When a measurable tumor (approximately $100 \mathrm{~mm}^{3}$ ) was observed at the injection site after 3 weeks, the mice were subjected to drug treatment. Based on body weight, the mice were randomly allocated into 3 groups, with 10 mice in each group: The LY8 group (injected with LY8 cells $+10 \mathrm{mg} / \mathrm{kg}$ rituximab), GW group (injected with the same dose of GW4869 medium $+10 \mathrm{mg} / \mathrm{kg}$ rituximab), and $\mathrm{EV}$ group (injected with $30 \mu \mathrm{g} \mathrm{EVs}+10 \mathrm{mg} / \mathrm{kg}$ rituximab). Five mice in each group were injected once a week and their tumors were measured every 4 days to record the long (A) and short (B) diameters of the tumors. The maximum diameter and volume of the tumor observed in the mice were $2 \mathrm{~cm}$ and $3.4 \mathrm{~cm}^{2}$, respectively. On the 28th day, the mice were sacrificed through cervical dislocation and tumors were removed.
The precise size of the tumor was measured using a Vernier caliper, and the tumor was weighed.

Statistical analysis. All data were processed using the IBM SPSS Statistics version 21.0 software (IBM Corp.). Data were first verified to show normal distribution and homogeneity of variance. Data were expressed as means \pm standard deviation or counts. An independent samples t-test or $\chi^{2}$ was used to compare two groups. One-way analysis of variance (ANOVA) was applied for comparison among multiple groups, followed by Tukey's multiple comparisons test. $\mathrm{P}<0.05$ indicated a statistically significant difference.

\section{Results}

TNFAIP3 is poorly expressed in DLBCL. DLBCL is the most common histological subtype of NHL (17-19) and generally responds well to treatment with rituximab $(20,21)$. TNFAIP3 is an established tumor suppressor in lymphoma (22-24), but its drug resistance has been reported in various types of cancer $(25,26)$. It has been hypothesized that TNFAIP3 


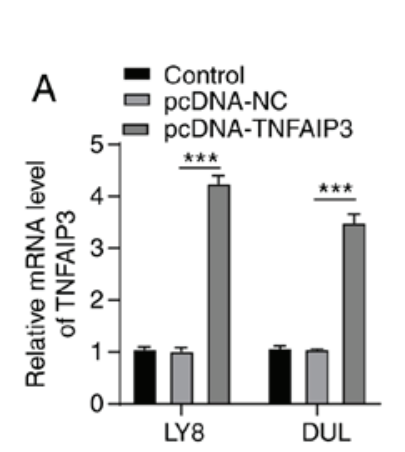

C
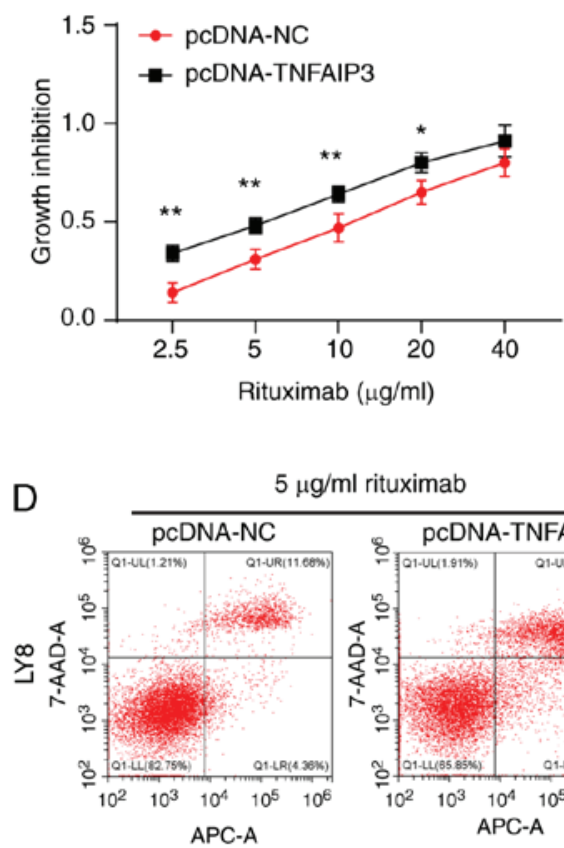

$5 \mu \mathrm{g} / \mathrm{ml}$ rituximab

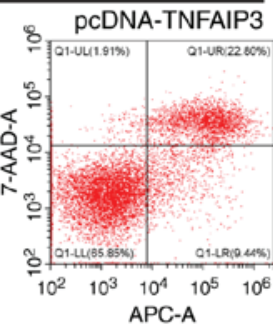

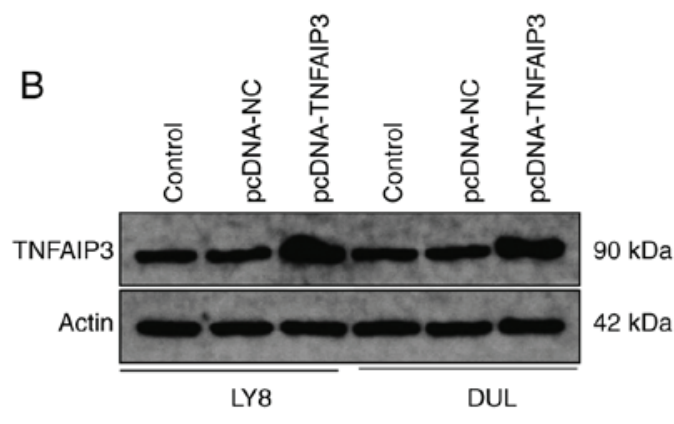

DUL

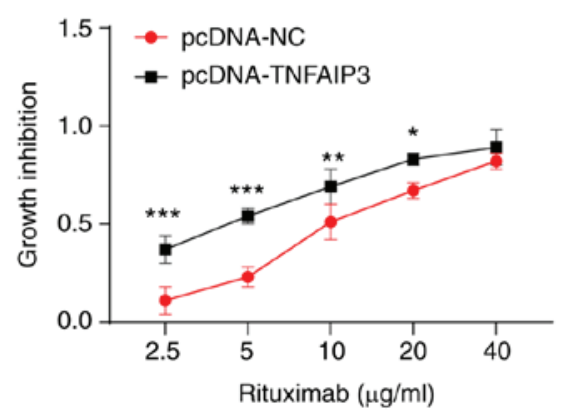

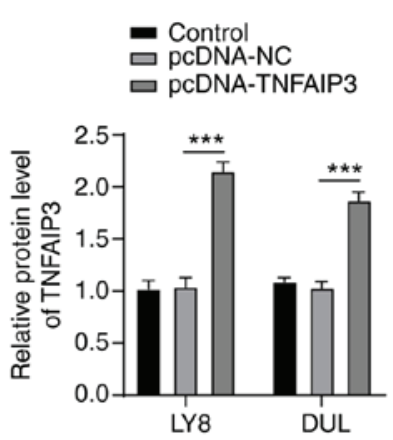

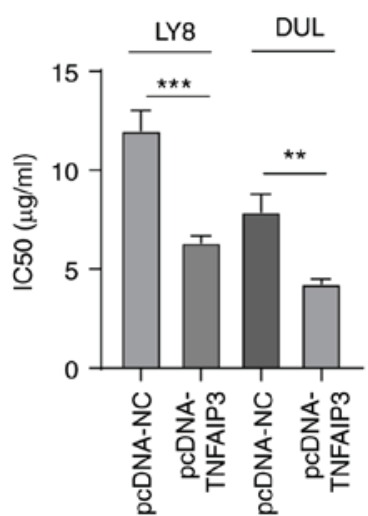

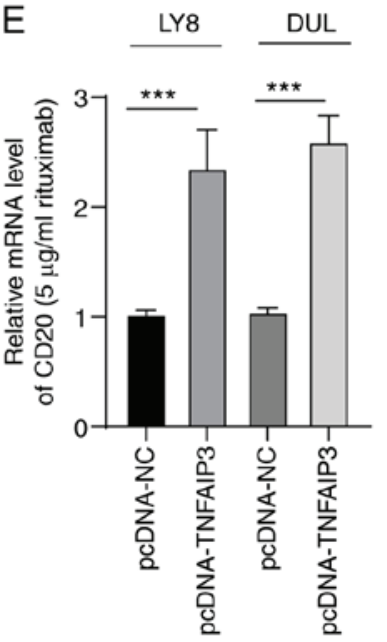

$\mathrm{F}$

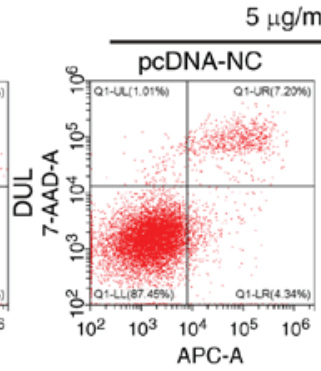

$\mu \mathrm{g} / \mathrm{ml}$ rituximab
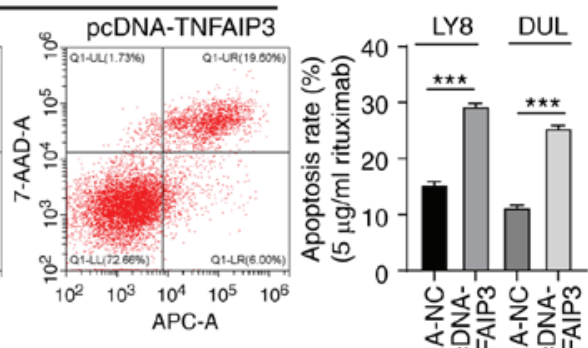

ising
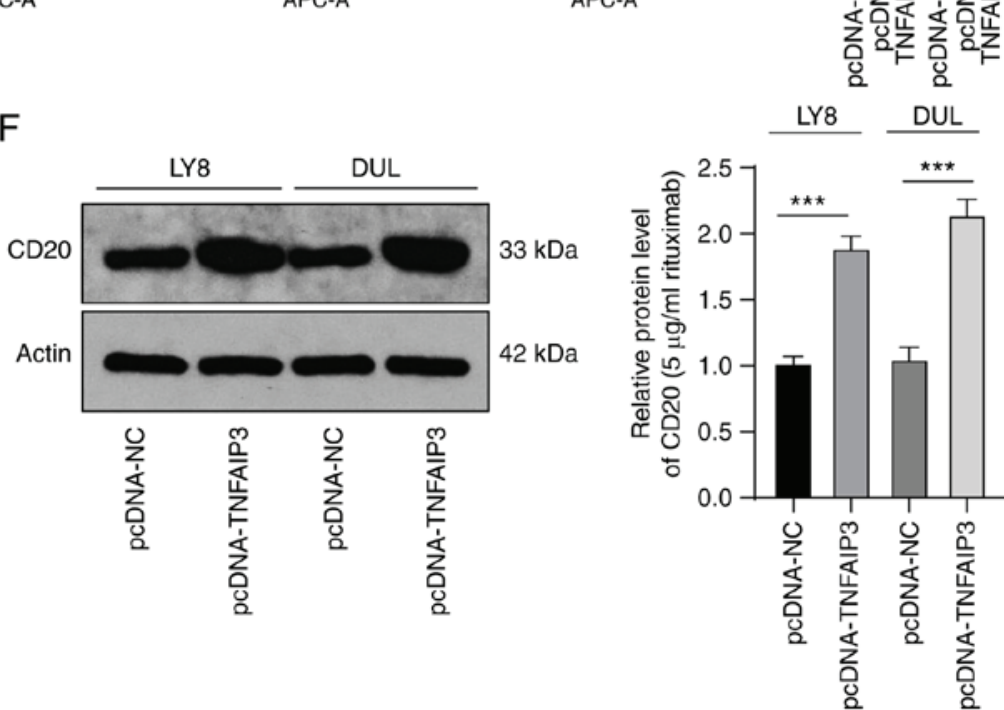

Figure 2. Overexpression of TNFAIP3 increases the sensitivity of DLBCL to rituximab. (A and B) Overexpression efficiency of pcDNA-TNFAIP3 transfection verified with RT-qPCR and western blotting. (C) Growth inhibition rate and IC50 value for DLBCL cells in each group, calculated using the MTT assay. (D) The apoptosis rate of DLBCL cells in each group determined with flow cytometry. (E and F) CD20 expression in DLBCL cells measured with RT-qPCR and western blotting. Experiments were performed three times. Data are expressed as means \pm standard deviations. Independent samples t-test was used to compare two groups in panels $\mathrm{C} / \mathrm{D} / \mathrm{E} / \mathrm{F}$. One-way ANOVA was used for comparisons among multiple groups in panels A/B, followed by Tukey's multiple comparisons test. ${ }^{*} \mathrm{P}<0.05,{ }^{* *} \mathrm{P}<0.01,{ }^{* * * *} \mathrm{P}<0.001$.

may be related to the resistance of DLBCL to rituximab. To determine the role of TNFAIP3 in DLBCL resistance to treatment, TNFAIP3 levels in patient lesions were first measured.
TNFAIP3 levels in the DLBCL group were significantly lower than those in the control group, and further decreased in the DLBCL-R group (all P<0.001) (Fig. 1A and B). Overall, 


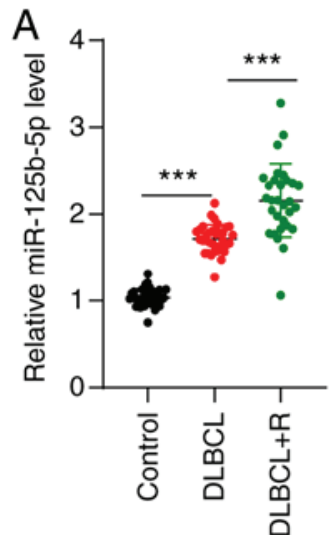

B

Binding Site of hsa-miR-125b-5p on TNFAIP3:

Show $10 \quad$ entries

TNFAIP3 WT: 5' gcuCAAGGAAG---CUCAGGGa 3 '

miR-125b-5p: 3' aguGUUCAAUCCCAGAGUCCCu 5'

TNFAIP3 MUT: 5' gcuGUUCGAAG---GAGUCCCa 3'

C

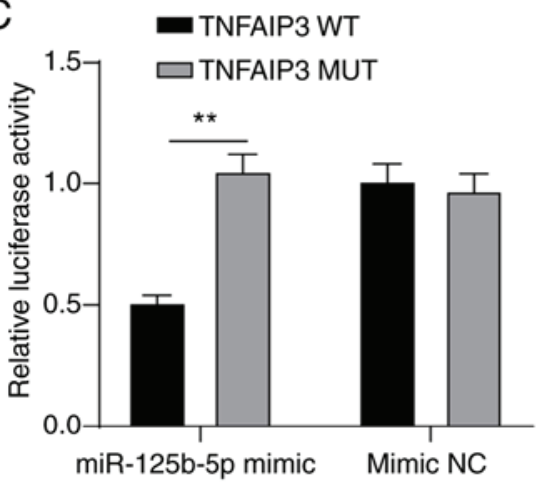

D

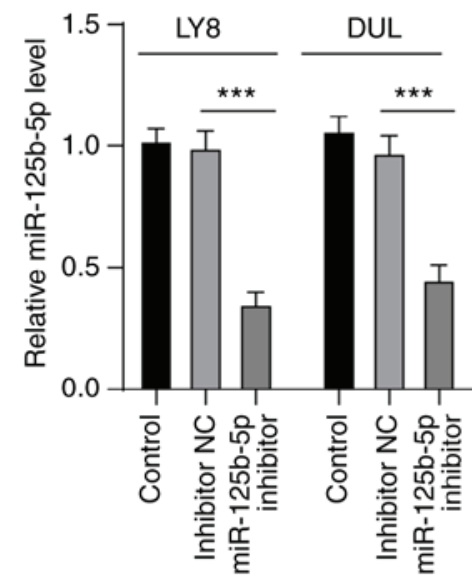

E

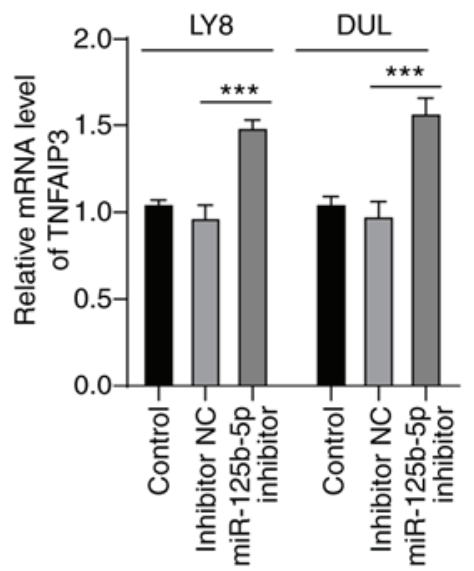

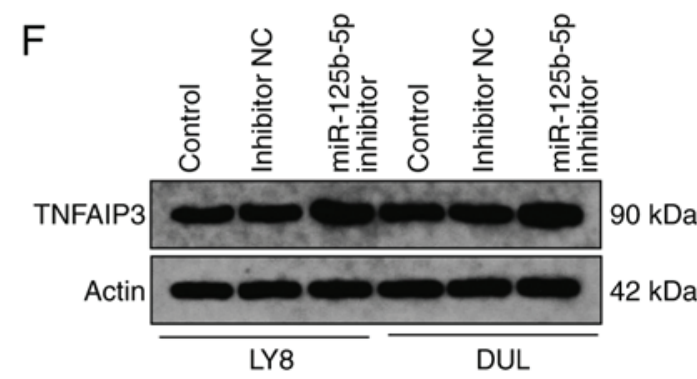

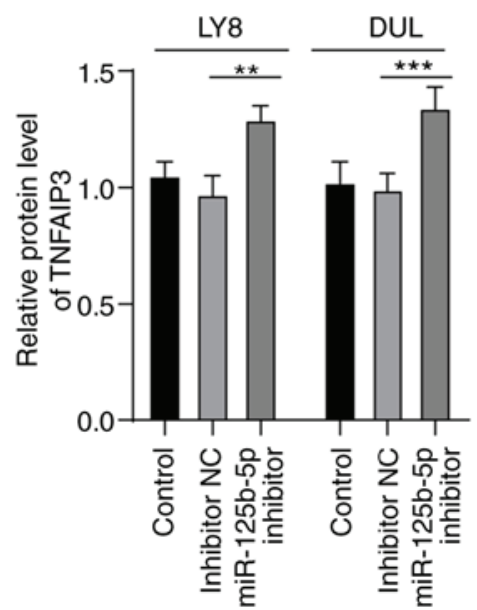

Figure 3. miR-125b-5p targets TNFAIP3 in DLBCL. (A) miR-125b-5p expression in tumor tissues, analyzed with RT-qPCR. (B) The binding site of miR-125b-5p with TNFAIP3 predicted using the starBase database. (C) The targeting relationship between miR-125b-5p and TNFAIP3 verified via dual-luciferase assay. (D) The effect of miR-125b-5p inhibition on miR-125b-5p expression analyzed with RT-qPCR. (E and F) TNFAIP3 expression in DLBCL cells with miR-125b-5p knockdown, analyzed with RT-qPCR and western blotting. The experiments were performed three times. Data are expressed as means \pm standard deviations. Data in panels A/D/E/F were analyzed using one-way ANOVA, followed by Tukey's multiple comparisons test; data in panel C were analyzed using the t-test. ${ }^{* *} \mathrm{P}<0.01,{ }^{* * *} \mathrm{P}<0.001$.

TNFAIP3 expression was low in DLBCL, which may be related to the development of DLBCL.

Overexpression of TNFAIP3 increases the sensitivity of DLBCL cells to rituximab. Next, in order to test our hypothesis, the TNFAIP3-expressing pcDNA vector was transfected into LY8 and DUL cells, which were then treated with different concentrations of rituximab. We confirmed the overexpression of TNFAIP3 with RT-qPCR and western blotting $(\mathrm{P}<0.001)$ (Fig. 2A and B). Results of the MTT assay demonstrated that the IC50 value for cells overexpressing TNFAIP3 was notably reduced compared with that 
A

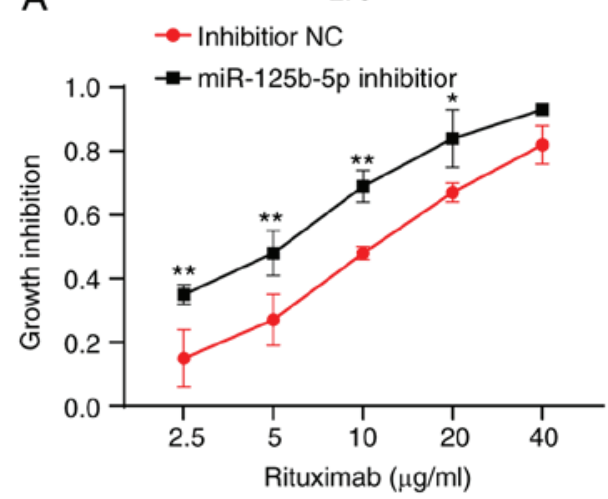

B

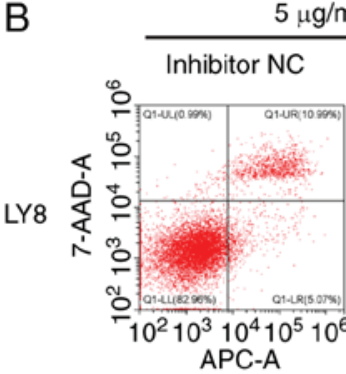

$5 \mu \mathrm{g} / \mathrm{ml}$ rituximab
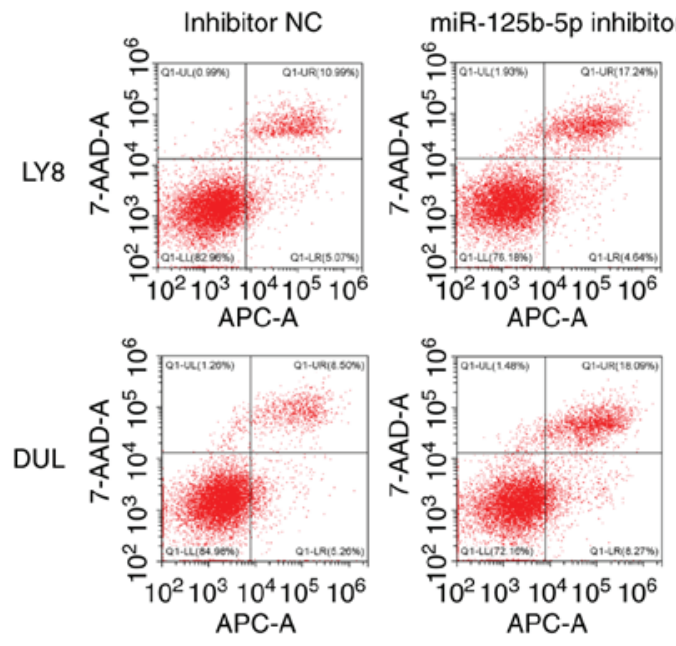

DUL

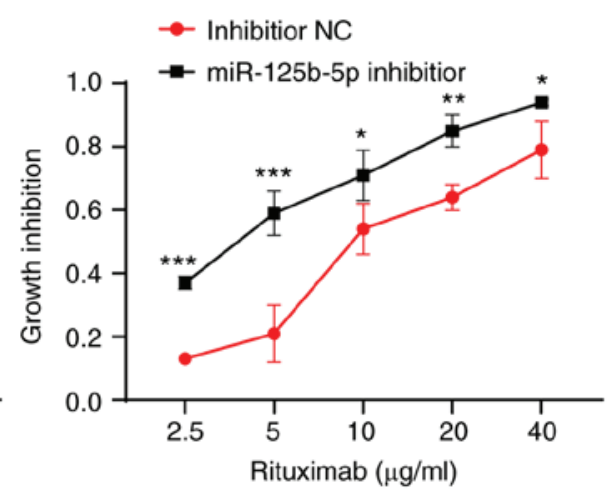

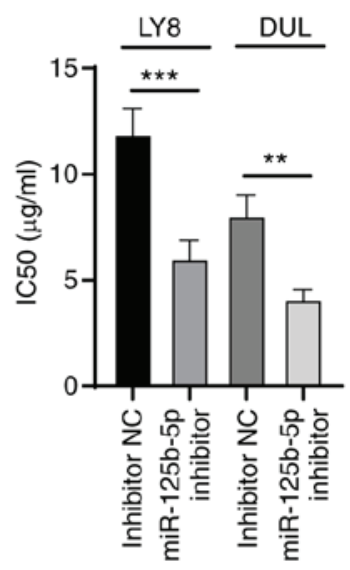

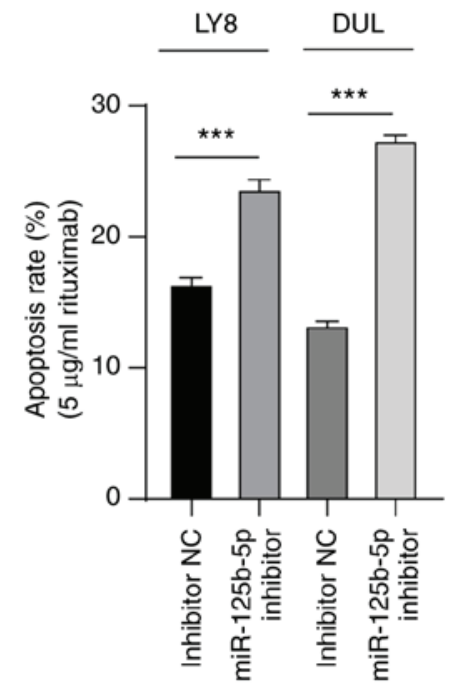

C

$\underline{\mathrm{LY} 8} \mathrm{DUL}$

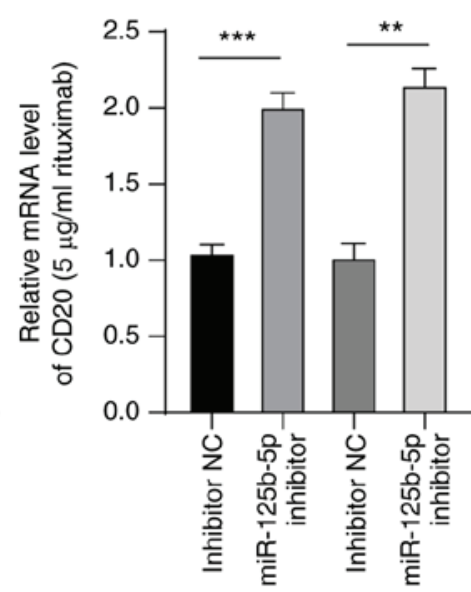

LY8

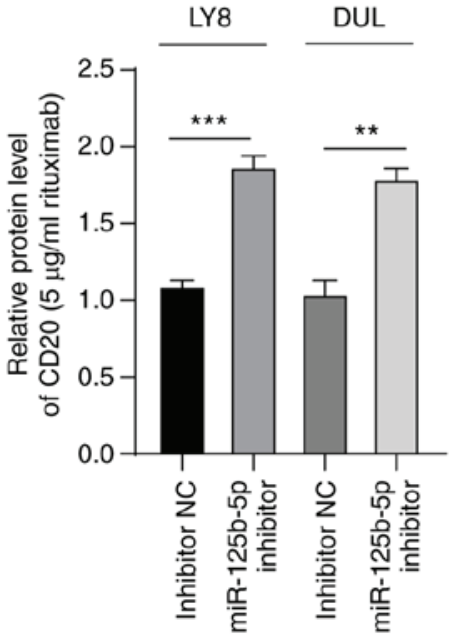

Figure 4. miR-125b-5p downregulation increases the sensitivity of DLBCL to rituximab. DLBCL cells were treated with an mir-125b-5p inhibitor or inhibitor NC and then with rituximab. (A) Growth inhibition rate and IC50 value of DLBCL cells in each group, calculated using the MTT assay. (B) The apoptosis rate of DLBCL cells determined with flow cytometry. (C and D) CD20 expression in DLBCL cells analyzed with RT-qPCR and western blotting. The experiments were performed three times. Data are expressed as means \pm standard deviations. Independent samples t-test was used to compare two groups. ${ }^{*} \mathrm{P}<0.05,{ }^{* *} \mathrm{P}<0.01$, ***: $\mathrm{P}<0.001$

for NC cells (LY8: $12.01 \pm 1.02$ vs. $6.35 \pm 0.35 \mu \mathrm{g} / \mathrm{ml}$; DUL: $7.89 \pm 0.89$ vs. $4.25 \pm 0.25 \mu \mathrm{g} / \mathrm{ml}$ ) (all $\mathrm{P}<0.001)$ (Fig. 2 C). The cells transfected with pcDNA-TNFAIP3 and treated with $5 \mu \mathrm{g} / \mathrm{ml}$ rituximab had a significantly higher cell apoptosis rate than the NC group $(\mathrm{P}<0.001)$ (Fig. 2D). Rituximab is a chimeric human-mouse monoclonal antibody targeting CD20 molecules on the B-cell surface (27). Therefore, we measured CD20 expression with RT-qPCR and western blotting and found that $\mathrm{CD} 20$ expression in the pcDNA-TNFAIP3 group was significantly increased compared with that in the NC 
A

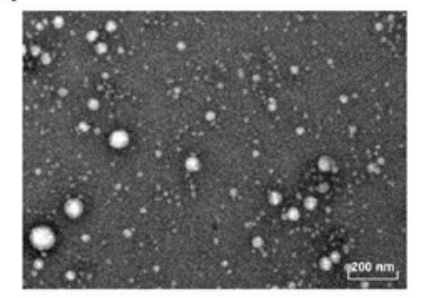

B

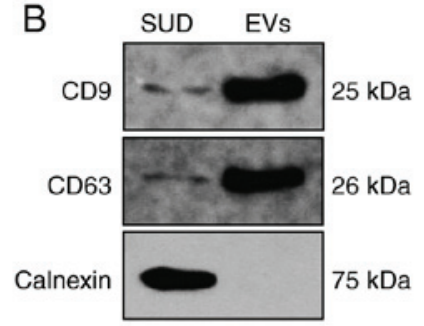

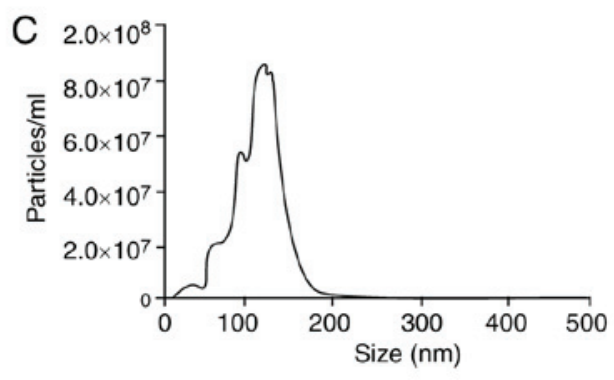

D

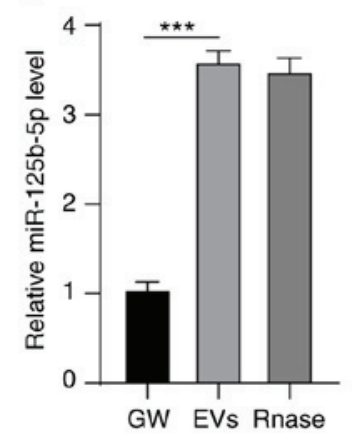

G

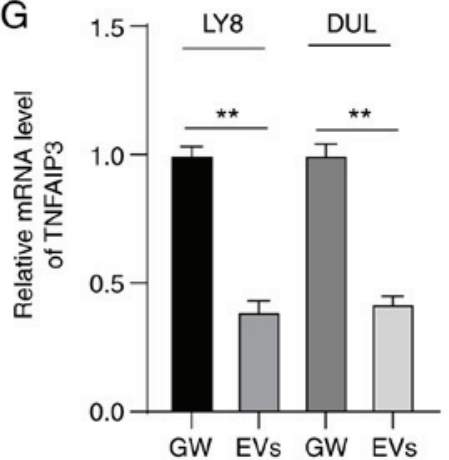

E

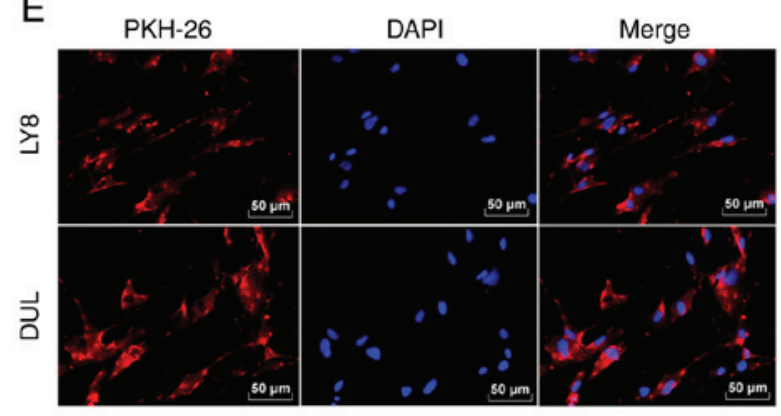

$\mathrm{F}$

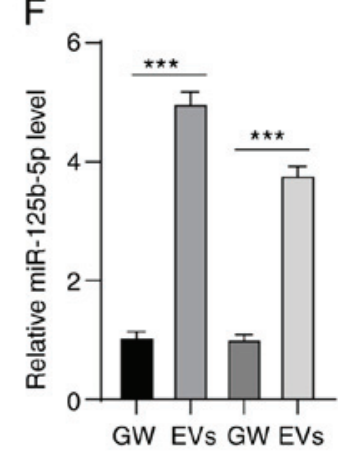

$\mathrm{H}$

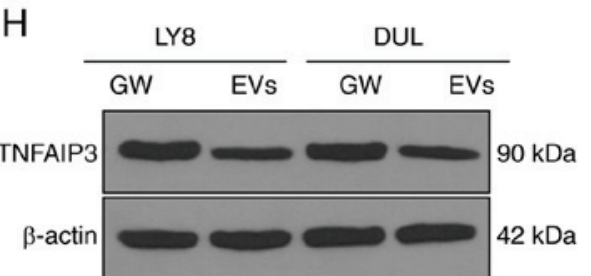

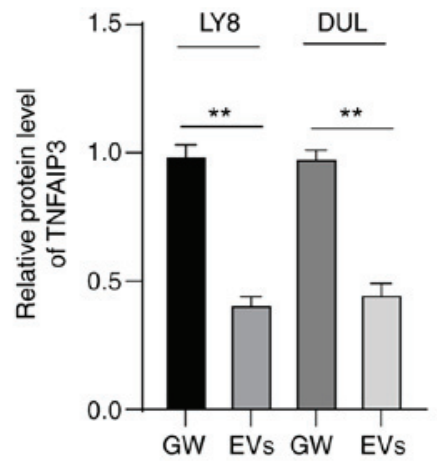

Figure 5. Extracellular vesicles (EVs) carry miR-125b-5p into DLBCL cells. (A) The morphology of EVs secreted by DLBCL cells observed under transmission electron microscope. (B) The expression of CD9, TSG101, and calnexin on the surface of SUD-EVs analyzed with western blotting. (C) The concentration and particle size of EVs measured with a nanoparticle tracking analyzer. (D) miR-125b-5p expression in EVs, analyzed with RT-qPCR. (E) DLBCL cells incubated with PKH-26-labeled SUD-EVs, observed under confocal microscope. (F) miR-125b-5p expression measured with RT-qPCR. (G and H) TNFAIP3 levels in DLBCL cells, analyzed with RT-qPCR and western blotting. The experiments were performed three times. Data are expressed as means \pm standard deviations. One-way ANOVA was used for comparisons among multiple groups in panel D, followed by Tukey's multiple comparisons test; t-test was used for comparisons between two groups in panels $\mathrm{F} / \mathrm{G} / \mathrm{H}$. ${ }^{* *} \mathrm{P}<0.01,{ }^{* * * *} \mathrm{P}<0.001$.

group $(\mathrm{P}<0.001)$ (Fig. $2 \mathrm{E}$ and $\mathrm{F})$. These results suggested that overexpression of TNFAIP3 increased DLBCL sensitivity to rituximab.

miR-125b-5p targets TNFAIP3. Previous findings have shown that miRs can inhibit the expression of tumor-specific genes in cancer (28). In order to explore the upstream molecular mechanism of TNFAIP3 in regulating the resistance of DLBCL to rituximab, we identified various miRs that target TNFAIP3, in the starBase database (29); among these, miR-125b-5p plays an important role in cancer and drug resistance $(30,31)$. Therefore, it was hypothesized that miR-125b-5p may regulate rituximab resistance in DLBCL by targeting TNFAIP3. miR-125b-5p expression was measured in patient lesions and it was found that miR-125b-5p expression in the DLBCL-R and DLBCL groups was significantly higher than that in the controls $(\mathrm{P}<0.001)$ (Fig. 3A). Then, according to TNFAIP3 and miR-125b-5p binding sites in the database, dual-luciferase experiments (Fig. 3B) verified the targeted binding relationship between TNFAIP3 and miR-125b-5p ( $\mathrm{P}<0.01)$ (Fig. 3C). In addition, miR-125b-5p expression in LY8 and DUL cells was significantly reduced using the miR-125b-5p inhibitor (both $\mathrm{P}<0.001$ ) (Fig. 3D), which in turn significantly increased TNFAIP3 expression in LY8 and DUL cells (all $\mathrm{P}<0.01$ ) (Fig. 3E and F). These results indicated that miR-125b-5p targeted TNFAIP3 in DLBCL.

miR-125b-5p downregulation increases the sensitivity of DLBCL cells to rituximab. To identify the role of miR-125b-5p in anti-DLBCL treatment, we used the miR-125b-5p inhibitor to intervene with miR-125b-5p expression in LY8 and DUL cells, and then treated the cells with different concentrations of rituximab. The results of the MTT assay revealed that the IC50 value for cells with low miR-125b-5p expression was notably reduced compared with that for NC cells (LY8: $11.89 \pm 1.21$ vs. $6.01 \pm 0.89 \mu \mathrm{g} / \mathrm{ml}$; DUL: $8.02 \pm 0.98$ vs. 

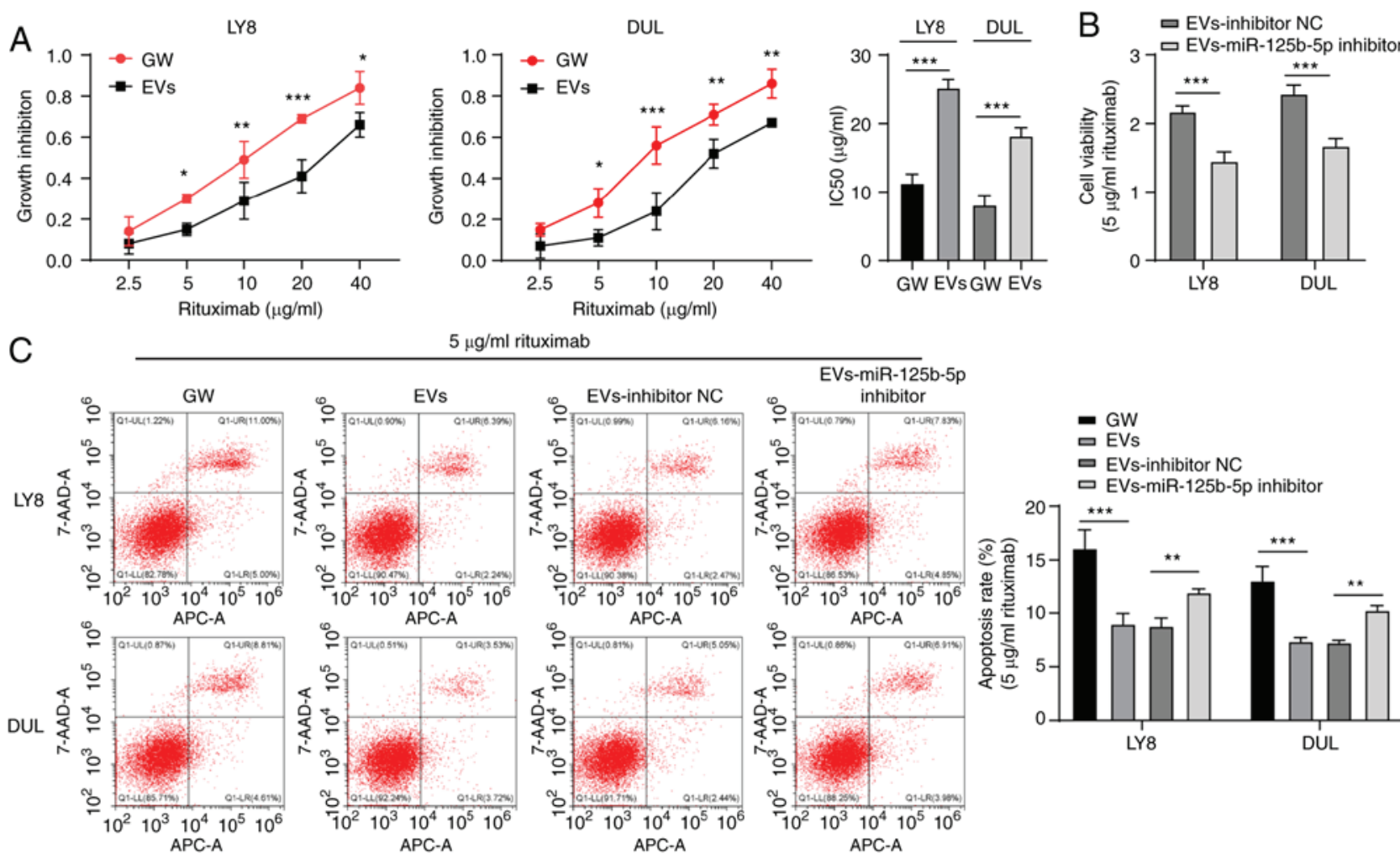

$5 \mu \mathrm{g} / \mathrm{ml}$ rituximab
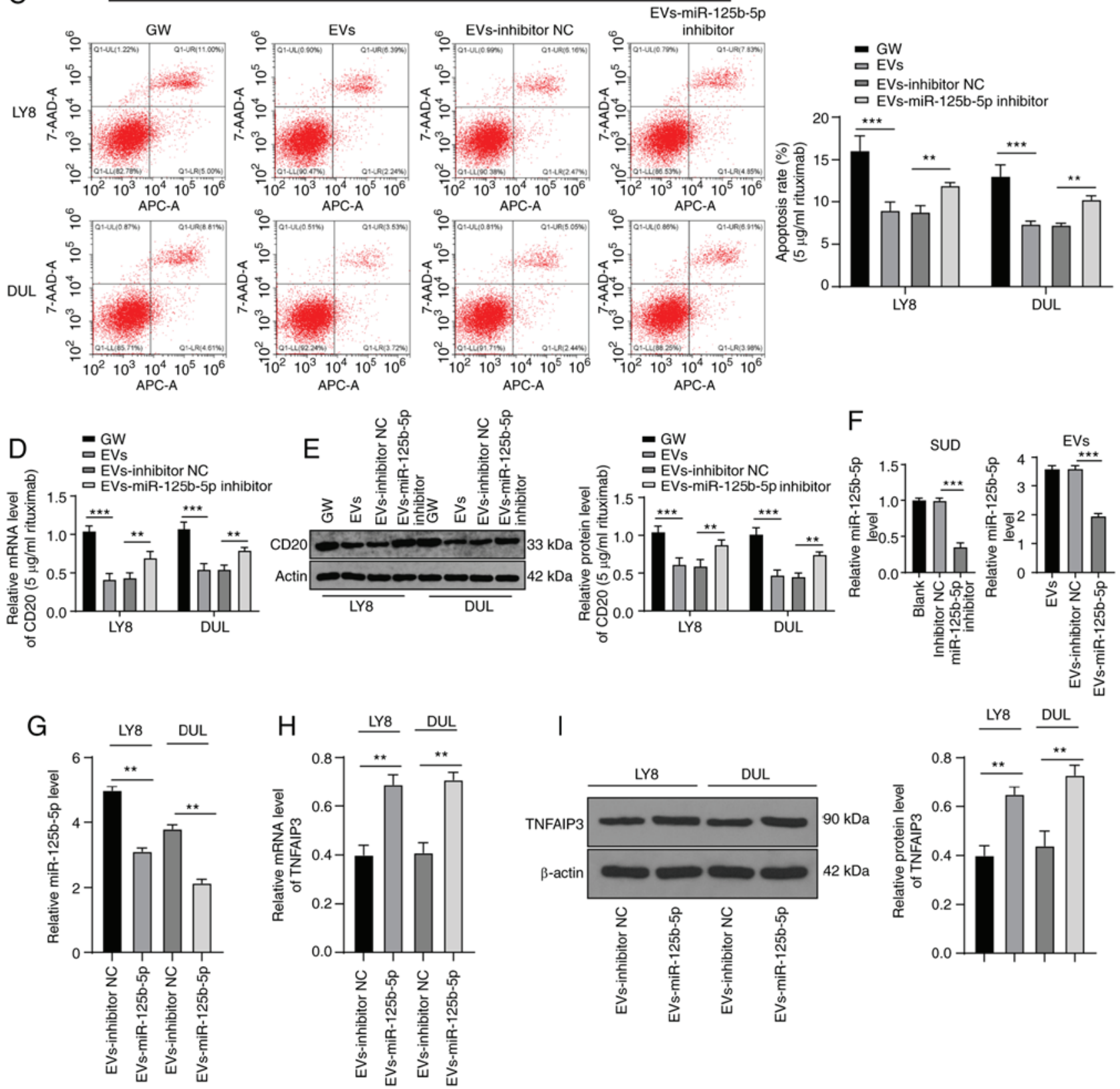

Figure 6. Extracellular vesicles (EVs) carrying miR-125b-5p reduce the sensitivity of DLBCL to rituximab. miR-125b-5p inhibitor was transfected into SUD cells, EVs were extracted, and then used with rituximab to treat LY8 and DUL cells. (A) Growth inhibition rate and IC50 value of DLBCL cells in each group, calculated using the MTT assay. (B) DLBCL cell viability determined using the MTT assay. (C) The apoptosis rate of DLBCL cells determined with flow cytometry. (D and E) CD20 expression in DLBCL, analyzed with RT-qPCR and western blotting. (F and G) miR-125b-5p expression in SUD, EVs, and DLBCL, analyzed with RT-qPCR. (H and I) TNFAIP3 levels in DLBCL cells, analyzed with RT-qPCR and western blotting. The experiments were performed three times. Data are expressed as means \pm standard deviations. One-way ANOVA was used for comparisons among multiple groups, followed by Tukey's multiple comparisons test; $\mathrm{t}$-test was used for comparisons between two groups in panels $\mathrm{A} / \mathrm{B} / \mathrm{G} / \mathrm{H} / \mathrm{I} .{ }^{*} \mathrm{P}<0.05,{ }^{* *} \mathrm{P}<0.01,{ }^{* * *} \mathrm{P}<0.001$.

$4.09 \pm 0.45 \mu \mathrm{g} / \mathrm{ml})($ all $\mathrm{P}<0.001)$ (Fig. 4A). The DLBCL cells treated with $5 \mu \mathrm{g} / \mathrm{ml}$ rituximab and miR-125b-5p inhibitor had a significantly higher apoptosis rate than the $\mathrm{NC}$ cells $(\mathrm{P}<0.001)$ (Fig. 4B). Furthermore, CD20 expression in these 

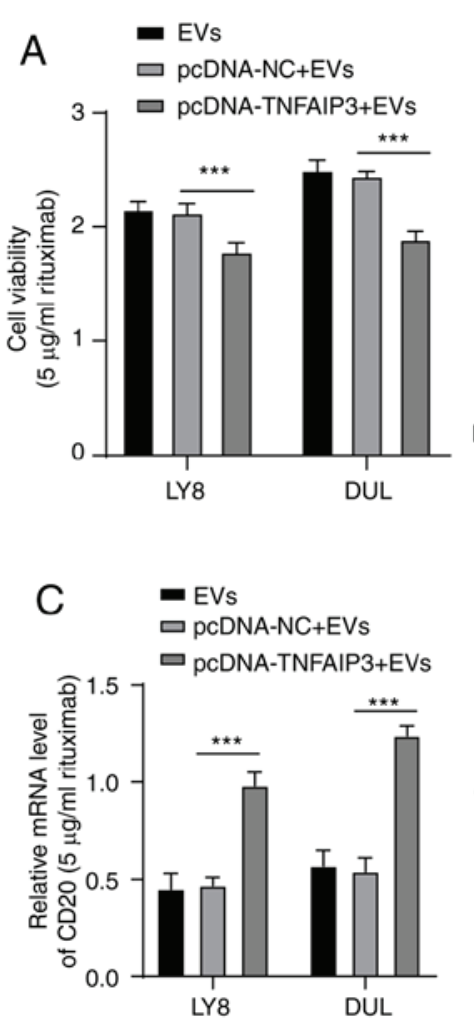

B

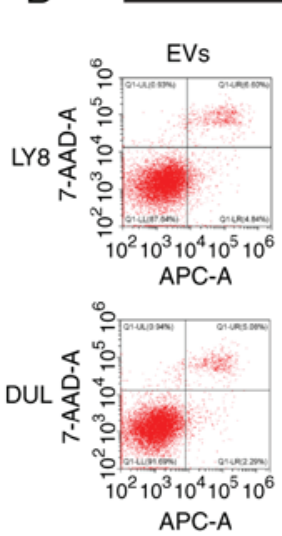

D

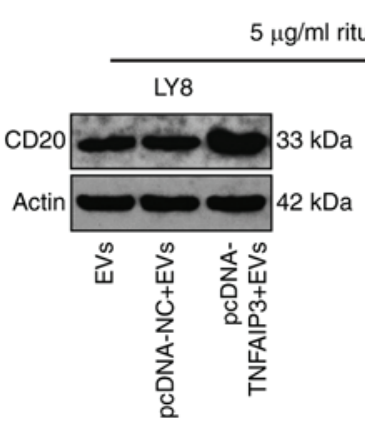

$5 \mu \mathrm{g} / \mathrm{ml}$ rituximab

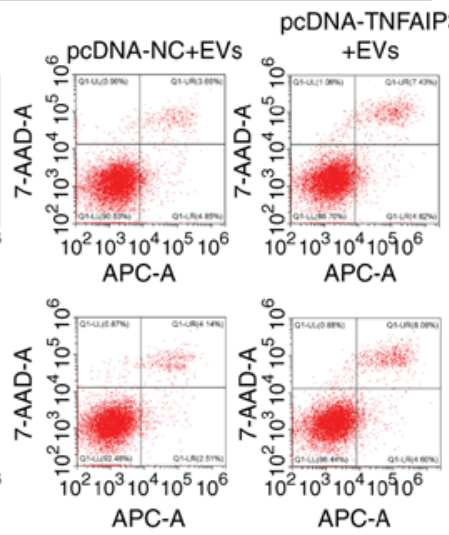

APC-A
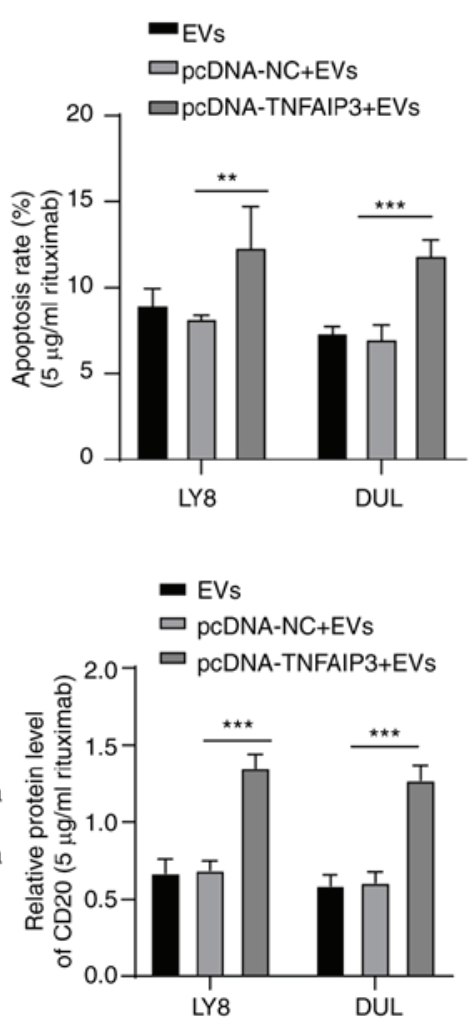

Figure 7. Overexpression of TNFAIP3 enhances the sensitivity of extracellular vesicle (EV)-treated DLBCL to rituximab. DLBCL cells were treated with pcDNA-TNFAIP3 or pcDNA-NC, incubated with EVs, and then treated with rituximab. (A) Cell viability determined by MTT assay. (B) The apoptosis rate of DLBCL cells determined with flow cytometry. (C and D) CD20 expression in DLBCL cells analyzed with RT-qPCR and western blotting. The experiments were performed three times. Data are expressed as means \pm standard deviations. One-way ANOVA was used for comparisons among multiple groups, followed by Tukey's multiple comparisons test. ${ }^{* *} \mathrm{P}<0.01,{ }^{* * *} \mathrm{P}<0.001$.

cells was significantly upregulated $(\mathrm{P}<0.001)$ (Fig. 4C and D). These results suggested that miR-125b-5p downregulation increased DLBCL sensitivity to rituximab.

EVs carry miR-125b-5p into DLBCL cells. Tumor EVs are important mediators for intercellular communication between tumor cells and other cells located, not only in the microenvironment, but also at further distances $(32,33)$. Recent findings have shown that the miRs carried by EVs play an important role in several diseases $(34,35)$. To validate the role of EVs in DLBCL resistance to rituximab, we first isolated EVs from DLBCL cells and observed their morphology. All EVs exhibited the classic tea tray shape (Fig. 5A). Western blotting results confirmed that the EV surface markers CD9 and CD63 were expressed in EVs isolated from SUD cells, while the endoplasmic reticulum marker calnexin was not expressed (Fig. 5B). NTA analysis revealed that EVs ranged from 45 to $165 \mathrm{~nm}$ in size, with an average size of $112 \mathrm{~nm}$ (Fig. 5C). These results indicated that EVs were successfully isolated from SUD cells. miR-125b-5p expression in the EV group was significantly higher than that in the GW4869 group, while there was no difference in expression between the EV and RNase groups (all $\mathrm{P}<0.001$ ) (Fig. 5D), indicating that miR-125b-5p was carried in SUD cell-derived EVs (SUD-EVs). EVs were successfully internalized by LY8 and DUL cells after incubation with the PKH-26-labeled SUD-EVs (Fig. 5E), resulting in significantly increased miR-125b-5p expression (all $\mathrm{P}<0.001$ )
(Fig. 5F) and significantly decreased TNFAIP3 expression $(\mathrm{P}<0.001)$ (Fig. 5G and $\mathrm{H}$ ). These results suggested that EVs can be internalized by DLBCL cells, carrying miR-125b-5p into DLBCL cells to upregulate miR-125b-5p expression. Additionally, miR-125b-5p can target TNFAIP3.

EV-carried miR-125b-5p reduces DLBCL sensitivity to rituximab. Next, EV-treated LY8 and DUL cells were incubated with different concentrations of rituximab. Results of the MTT assay demonstrated that the IC50 value for EV-treated LY8 and DUL cells was significantly enhanced (LY8: 11.32 \pm 1.32 vs. $25.21 \pm 1.23 \mu \mathrm{g} / \mathrm{ml}$; DUL: $8.12 \pm 1.39$ vs. $18.21 \pm 1.21 \mu \mathrm{g} / \mathrm{ml})$ (all $\mathrm{P}<0.001$ ) (Fig. 6A). Next, we calculated the apoptotic rate of cells treated with $5 \mu \mathrm{g} / \mathrm{ml}$ rituximab combined with EVs or GW4869. The apoptotic rate and CD20 expression in the EV group were significantly decreased (all $\mathrm{P}<0.01$ ) (Fig. 6C-E). To further verify whether the miR-125b-5p carried by EVs is involved in DLBCL sensitivity to rituximab, we employed the miR-125b-5p inhibitor to reduce miR-125b-5p expression in SUD cells, extracted the EVs, and found that miR-125b-5p expression in the EVs was reduced (Fig. 6F). Then, the obtained EVs were incubated with LY8 and DUL cells and treated with $5 \mu \mathrm{g} / \mathrm{ml}$ rituximab. miR-125b-5p expression in the LY8 and DUL cells incubated with the obtained miR-125b-5p-inhibitor-EVs was reduced (Fig. 6G), and TNFAIP3 expression was significantly increased $(\mathrm{P}<0.01)$ (Fig. $6 \mathrm{H}$ and $\mathrm{I})$. Moreover, the activity of these cells was significantly decreased (Fig. 6B) 
A

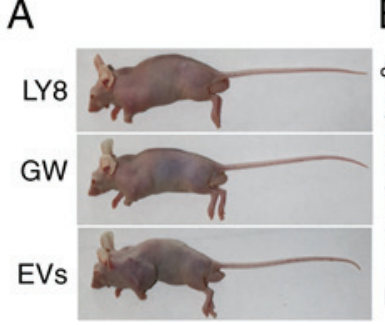

B

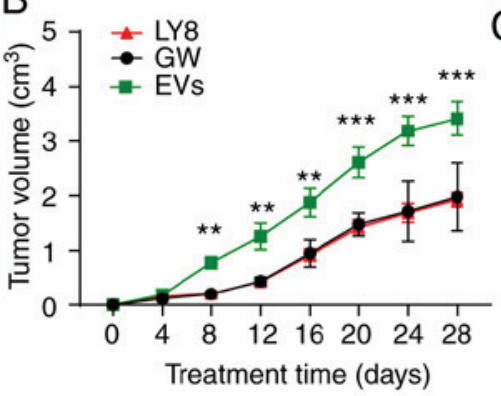

C

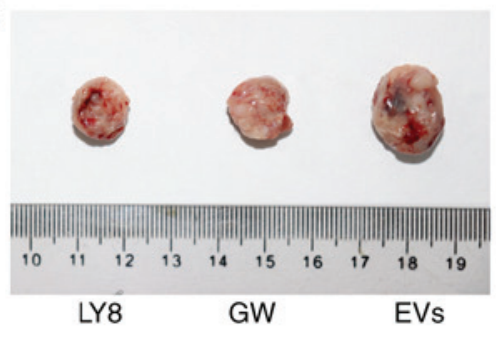

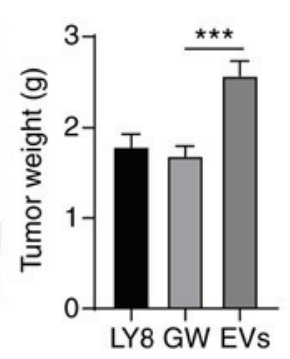

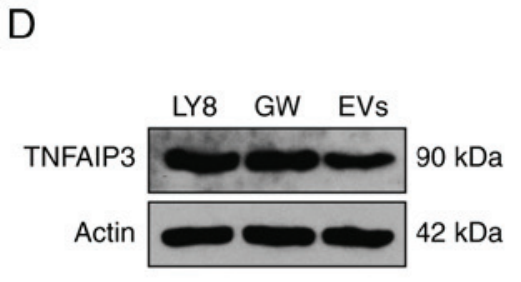

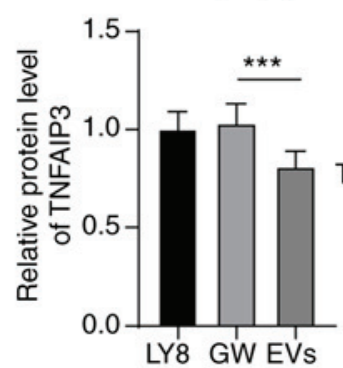

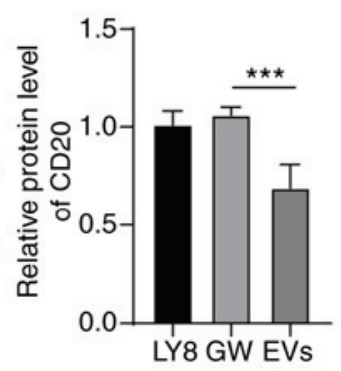

Figure 8. Extracellular vesicles (EVs) reduce the sensitivity of DLBCL model mice to rituximab through the miR-125b-5p/TNFAIP3 axis. Subcutaneous injection with LY8 cells was used to establish the DLBCL mouse model. Mice were treated with the conditioned medium from SUV cells treated with GW4869, and EVs. Mice in both groups were treated with rituximab. (A) Mice were examined regularly. (B) Tumor volume on different days. (C) Tumor weight in each group. (D) TNFAIP3 and CD20 levels in mouse tumors analyzed by western blotting (N=5). Data are expressed as means \pm standard deviations. One-way ANOVA was used for comparisons among multiple groups, followed by Tukey's multiple comparisons test. ${ }^{* *} \mathrm{P}<0.01,{ }^{* * * *} \mathrm{P}<0.001$.

and the apoptosis rate (Fig. 6C) and CD20 expression level (Fig. 6D and E) were significantly increased (all $\mathrm{P}<0.01$ ). In summary, the miR-125b-5p carried by EVs reduced the sensitivity of DLBCL to rituximab.

Overexpression of TNFAIP3 increases the sensitivity of EV-treated DLBCL cells to rituximab. Next, a combined experiment was performed to verify that the EV-carried miR-125b-5p increased DLBCL resistance to rituximab by affecting TNFAIP3. The EVs isolated from LY8 cells were incubated with LY8 and DUL cells transfected with pcDNA-TNFAIP3 or pcDNA-NC, followed by treatment with $5 \mu \mathrm{g} / \mathrm{ml}$ rituximab. Compared with that of the $\mathrm{NC}$ groups, the activity of cells in the pcDNA-TNFAIP3 + EV group was significantly decreased (Fig. 7A) and the apoptosis rate (Fig. 7B) and CD20 expression level were significantly increased (all $\mathrm{P}<0.001$ ) (Fig. 7C and D). These results suggested that overexpression of TNFAIP3 enhanced the sensitivity of EV-treated DLBCL to rituximab.

EVs reduce DLBCL sensitivity to rituximab via the miR-125b-5p/TNFAIP3 axis. Based on the evidence that EVs can increase the resistance of DLBCL cells to rituximab, we further verified this effect in a mouse model. Subcutaneous injection of LY8 cells into mice resulted in the localized formation of tumor tissue masses. Mice were treated with EVs, GW4869 medium, and rituximab, and their tumors were monitored and finally extracted for measurement (Fig. 8A). In the GW group, rituximab significantly inhibited tumor growth, while the volume and weight of tumors in the EV group were significantly increased (all $\mathrm{P}<0.05$ ) (Fig. 8B and $\mathrm{C}$ ). In addition, the expression levels of TNFAIP3 and CD20 in the EV group were significantly lower than those in the GW group (all $\mathrm{P}<0.01$ ) (Fig. 8D). Collectively, the results indicated that
EVs can reduce the sensitivity of DLBCL mice to rituximab through the miR-125b-5p/TNFAIP3 axis.

\section{Discussion}

TNFAIP3 is frequently inactivated in B-cell lymphomas (24), and in particular, is deleted in $18-50 \%$ of DLBCL cases (8). miRs transported by EVs have received great attention due to their roles in intercellular communication in B-cell lymphomagenesis, possibly by targeting downstream mRNAs (36). Therefore, we hypothesized that TNFAIP3 is targeted by an exosomal shuttled miR in DLBCL cells. As expected, the results of our in vitro and in vivo experiments supported the finding that tumor-derived EVs released miR-125b-5p into DLBCL cells, which targeted TNFAIP3, thus reducing DLBCL sensitivity to rituximab.

Previous findings have emphasized that TNFAIP3 alterations are involved in DLBCL pathogenesis $(7,37)$. In the present study, TNFAIP3 expression levels in DLBCL patients were lower than those in control individuals, and were further decreased in DLBCL-R patients, which concurred with the results of a previous study in which TNFAIP3 insufficiency was associated with negative prognosis of DLBCL (8). Then, TNFAIP3 expression in DLBCL cells was enhanced by transfection with pcDNA, followed by treatment with different concentrations of rituximab. The IC50 value for TNFAIP3-overexpressing cells was notably reduced and the apoptosis rate was increased. The expression of CD20 in EVs released from B-cell lymphoma cells has been reported to be negatively correlated with rituximab treatment $(27,38)$. In the current study, CD20 expression in the TNFAIP3-overexpressing DLBCL cells was significantly increased. TNFAIP3-deficient cells were previously shown to stably generate B-cell lymphomas in immunodeficient mice, whereas tumorigenicity was effectively blocked by TNFAIP3 
restoration (39). Of note, TNFAIP3 deletion has been reported to be marginally associated with favorable prognosis in rituximab-treated populations (9). Overall, overexpression of TNFAIP3 increased the sensitivity of DLBCL to rituximab.

The risk of drug resistance is reportedly 2.14-fold higher in DLBCL patients with abnormal miR expression (14). We predicted that miR-125b-5p would be involved in the upstream mechanism of TNFAIP3 in DLBCL resistance to rituximab, based on its extensive involvement in cancer and drug resistance $(30,31)$. miR-125b-5p expression in DLBCL-R and DLBCL patients was higher than that in the control individuals. miR-125b and miR-125b-5p are both reportedly upregulated in rituximab-chemoresistant patients $(40,41)$, and miR-125b reportedly inhibits TNFAIP3 in DLBCL (42). The dual-luciferase experiments in the current study verified the targeted binding relationship between TNFAIP3 and miR-125b-5p. Subsequently, miR-125b-5p expression in DLBCL cells was suppressed using the miR-125b-5p inhibitor and the cells were treated with different concentrations of rituximab. The IC50 value for cells with low miR-125b-5p expression was notably reduced, while the apoptosis rate and CD20 expression level were increased. miR-125b silencing is required for normal B-cell development (43). Indeed, miR-125b was reportedly upregulated in doxorubicin-resistant Ewing sarcoma, while miR-125b knockdown enhanced sensitivity to doxorubicin (44). Rituximab-resistant DLBCL in patients with miR-125b overexpression is more likely to be refractory to other chemotherapy regimens (41). Briefly, miR-125b-5p downregulation sensitized DLBCL cells to rituximab.

Tumor-derived exosomal miRs play key roles in tumor chemoresistance (45). Increasing evidence supports the significance of EVs in DLBCL progression and response or resistance to therapies (13). We hypothesized that miR-125b-5p may be released from SUD cell-derived EVs. Our results demonstrated that miR-125b-5p expression in the EV group was higher than that in the GW4869 group, with no difference observed between the EV and RNase groups, indicating that miR-125b-5p was released by EVs. Exosomal miR-125b-5p is also described as a potential prognostic predictor of chemoresistance in the serum of patients with DLBCL (40). Furthermore, the IC50 value for EV-treated DLBCL cells was significantly enhanced, while the apoptosis rate and CD20 expression were notably decreased. In summary, EVs can be internalized by DLBCL cells, carrying miR-125b-5p that upregulates miR-125b-5p expression, thus reducing DLBCL sensitivity to rituximab.

Next, a combined experiment was performed to verify that the miR-125b-5p carried by EVs increased DLBCL resistance to rituximab by affecting TNFAIP3. pcDNA-transfected DLBCL cells were treated with LY8-EVs and rituximab, resulting in decreased activity and enhanced apoptosis rate and CD20 expression. B-cell lymphoma-derived EVs carry the CD20 target antigen and act as bait, enabling lymphoma cells to evade immunotherapy (38). These findings suggest that overexpression of TNFAIP3 can enhance the sensitivity of EV-treated DLBCL to rituximab. Moreover, rituximab significantly inhibited tumor growth in vivo, the effects of which were annulled by $\mathrm{EV}$ + rituximab treatment. B-cell lymphoma-derived EVs have been reported to rescue lymphoma cells from the complement-dependent cytotoxicity induced by rituximab (46). In addition, enhanced cytolytic activity against rituximab-treated tumor cells has been observed after the removal of lymphoma cell EVs (38). In the current study, the expression levels of TNFAIP3 and CD20 in the EV group were lower than those in the GW group. Taken together, our results support the finding that EVs reduced the sensitivity of DLBCL model mice to rituximab through the miR-125b-5p/TNFAIP3 axis.

Results of the present study demonstrated that the EVs carrying miR-125b-5p can reduce DLBCL sensitivity to rituximab by inhibiting TNFAIP3 expression. However, the regulatory mechanism of the miR-125b-5p/TNFAIP3 axis in the sensitivity of DLBCL to rituximab requires further investigation. Whether the miR-125b-5p/TNFAIP3 axis can be used as a therapeutic approach for DLBCL also requires further study. Future studies aim to focus on the pathways downstream of the miR-125b-5p/TNFAIP3 axis that influence the sensitivity of DLBCL to rituximab.

\section{Acknowledgements}

Not applicable.

\section{Funding}

This study was supported by The Key Research Project from Science and Technology Department of Sichuan Province (no. 2019YFS0301); Doctor Research Foundation of The Affiliated Hospital of Southwest Medical University (nos. 19032 and 19079); The Key Research Project from Health and Family Planning Commission of Sichuan Province (no. 18ZD014); Applied Basic Research Project of Luzhou Science and Technology Bureau (2019LZXNYDJ54).

\section{Availability of data and materials}

The analyzed data sets generated during the study are available from the corresponding author on reasonable request.

\section{Authors' contributions}

LZ conceived and designed the study. SXZ, TJZ, XML and JLT contributed to research, conducting of experiments, analysis and review of data, as well as the writing and editing of the manuscript. All authors read and approved the final manuscript.

\section{Ethics approval and consent to participate}

Study approval was obtained from the Ethics Committee of The Affiliated Hospital of Southwest Medical University (no. 20180306006). The clinical registration number is KY2019091. Patient consent was obtained from the patients. Animal experiments were implemented on the guide for the care and use of laboratory animals.

\section{Patient consent for publication}

Not applicable.

\section{Competing interests}

The authors declare that they have no competing interests. 


\section{References}

1. Harker-Murray PD, Pommert L and Barth MJ: Novel therapies potentially available for pediatric B-cell non-hodgkin lymphoma. J Natl Compr Canc Netw 18: 1125-1134, 2020.

2. Allen P: Diffuse large B-cell lymphoma in the elderly: Current approaches. Curr Oncol Rep 22: 114, 2020.

3. Liu Y and Barta SK: Diffuse large B-cell lymphoma: 2019 update on diagnosis, risk stratification, and treatment. Am J Hematol 94: 604-616, 2019.

4. Maurer MJ, Jais JP, Ghesquieres H, Witzig TE, Hong F, Haioun C, Thompson CA, Thieblemont C, Micallef IN, Porrata LF, et al Personalized risk prediction for event-free survival at 24 months in patients with diffuse large B-cell lymphoma. Am J Hematol 91: 179-184, 2016

5. Giulino L, Mathew S, Ballon G, Chadburn A, Barouk S, Antonicelli G, Leoncini L, Liu YF, Gogineni S, Tam W and Cesarman E: A20 (TNFAIP3) genetic alterations in EBV-associated AIDS-related lymphoma. Blood 117: 4852-4854, 2011.

6. Hovelmeyer N, Reissig S, Xuan NT, Adams-Quack P, Lukas D, Nikolaev A, Schluter D and Waisman A: A20 deficiency in B cells enhances B-cell proliferation and results in the development of autoantibodies. Eur J Immunol 41: 595-601, 2011.

7. Fujii M, Takata K, Chuang SS, Miyata-Takata T, Ando M, Sato Y and Yoshino T: A20 (TNFAIP3) alterations in primary intestinal diffuse large B-cell lymphoma. Acta Med Okayama 72: 23-30, 2018.

8. Dong G, Chanudet E, Zeng N, Appert A, Chen YW, Au WY, Hamoudi RA, Watkins AJ, Ye H, Liu H, et al: A20, ABIN-1/2, and CARD11 mutations and their prognostic value in gastrointestinal diffuse large B-cell lymphoma. Clin Cancer Res 17: 1440-1451, 2011

9. Paik JH, Go H, Nam SJ, Kim TM, Heo DS, Kim CW and Jeon YK: Clinicopathologic implication of A20/TNFAIP3 deletion in diffuse large B-cell lymphoma: An analysis according to immunohistochemical subgroups and rituximab treatment. Leuk Lymphoma 54: 1934-1941, 2013.

10. Cappariello A and Rucci N: Tumour-derived extracellular vesicles (EVs): A dangerous 'message in a bottle' for bone. Int J Mol Sci 20: 4805, 2019.

11. Urabe F, Kosaka N, Ito K, Kimura T, Egawa S and Ochiya T: Extracellular vesicles as biomarkers and therapeutic targets for cancer. Am J Physiol Cell Physiol 318: C29-C39, 2020.

12. Liu W, Zhu M, Wang H, Wang W and Lu Y: Diffuse large B cell lymphoma-derived extracellular vesicles educate macrophages to promote tumours progression by increasing PGC-1 $\beta$. Scand J Immunol 91: e12841, 2020.

13. Rutherford SC, Fachel AA, Li S, Sawh S, Muley A, Ishii J, Saxena A, Dominguez PM, Caldas Lopes E, Agirre X, et al: Extracellular vesicles in DLBCL provide abundant clues to aberrant transcriptional programming and genomic alterations. Blood 132: e13-e23, 2018.

14. Ting CY, Liew SM, Price A, Gan GG, Bee-Lan Ong D, Tan SY and Bee PC: Clinical significance of aberrant microRNAs expression in predicting disease relapse/refractoriness to treatment in diffuse large B-cell lymphoma: A meta-analysis. Crit Rev Oncol Hematol 144: 102818, 2019.

15. Xu ZZ, Wang WF, Fu WB, Wang AH, Liu ZY, Chen LY, Guo P and Li JM: Combination of rituximab and mammalian target of rapamycin inhibitor everolimus (RAD001) in diffuse large B-cell lymphoma. Leuk Lymphoma 55: 1151-1157, 2014.

16. Livak KJ and Schmittgen TD: Analysis of relative gene expression data using real-time quantitative PCR and the 2(-Delta Delta C(T)) method. Methods 25: 402-408, 2001.

17. Li S, Young KH and Medeiros LJ: Diffuse large B-cell lymphoma Pathology 50: 74-87, 2018.

18. Sarkozy C and Sehn LH: Management of relapsed/refractory DLBCL. Best Pract Res Clin Haematol 31: 209-216, 2018.

19. Tamma R, Ranieri G, Ingravallo G, Annese T, Oranger A, Gaudio F, Musto P, Specchia G and Ribatti D: Inflammatory cells in diffuse large B cell lymphoma. J Clin Med 9: 2418, 2020.

20. Habermann TM, Weller EA, Morrison VA, Gascoyne RD, Cassileth PA, Cohn JB, Dakhil SR, Woda B, Fisher RI, Peterson BA and Horning SJ: Rituximab-CHOP versus CHOP alone or with maintenance rituximab in older patients with diffuse large B-cell lymphoma. J Clin Oncol 24: 3121-3127, 2006.
21. Mounier N, Briere J, Gisselbrecht C, Emile JF, Lederlin P, Sebban C, Berger F, Bosly A, Morel P, Tilly H, et al: Rituximab plus CHOP (R-CHOP) overcomes bcl-2-associated resistance to chemotherapy in elderly patients with diffuse large B-cell lymphoma (DLBCL). Blood 101: 4279-4284, 2003.

22. Honma K, Tsuzuki S, Nakagawa M, Tagawa H, Nakamura S, Morishima Y and Seto M: TNFAIP3/A20 functions as a novel tumor suppressor gene in several subtypes of non-Hodgkin lymphomas. Blood 114: 2467-2475, 2009.

23. Schmitz R, Hansmann ML, Bohle V, Martin-Subero JI, Hartmann S, Mechtersheimer G, Klapper W, Vater I, Giefing M, Gesk S, et al: TNFAIP3 (A20) is a tumor suppressor gene in Hodgkin lymphoma and primary mediastinal B cell lymphoma. J Exp Med 206: 981-989, 2009.

24. Vereecke L, Beyaert R and van Loo G: The ubiquitin-editing enzyme A20 (TNFAIP3) is a central regulator of immunopathology. Trends Immunol 30: 383-391, 2009.

25. Chen S, Xing H, Li S, Yu J, Li H, Liu S, Tian Z, Tang K, Rao Q, Wang $\mathrm{M}$ and Wang J: Up-regulated A20 promotes proliferation, regulates cell cycle progression and induces chemotherapy resistance of acute lymphoblastic leukemia cells. Leuk Res 39: 976-983, 2015.

26. da Silva CG, Minussi DC, Ferran C and Bredel M: A20 expressing tumors and anticancer drug resistance. Adv Exp Med Biol 809: 65-81, 2014.

27. Palanichamy A, Jahn S, Nickles D, Derstine M, Abounasr A, Hauser SL, Baranzini SE, Leppert D and von Budingen HC: Rituximab efficiently depletes increased CD20-expressing $\mathrm{T}$ cells in multiple sclerosis patients. J Immunol 193: 580-586, 2014.

28. Calin GA and Croce CM: MicroRNA signatures in human cancers. Nat Rev Cancer 6: 857-866, 2006.

29. Li JH, Liu S, Zhou H, Qu LH and Yang JH: starBase v2.0: Decoding miRNA-ceRNA, miRNA-ncRNA and protein-RNA interaction networks from large-scale CLIP-Seq data. Nucleic Acids Res 42: D92-D97, 2014.

30. Liu S, Chen Q and Wang Y: MiR-125b-5p suppresses the bladder cancer progression via targeting $\mathrm{HK} 2$ and suppressing PI3K/AKT pathway. Hum Cell 33: 185-194, 2020.

31. Yao J, Li Z, Wang X, Xu P, Zhao L and Qian J: MiR-125a regulates chemo-sensitivity to gemcitabine in human pancreatic cancer cells through targeting A20. Acta Biochim Biophys Sin (Shanghai) 48: 202-208, 2016.

32. Kara-Terki L, Treps L, Blanquart C and Fradin D: Critical roles of tumor extracellular vesicles in the microenvironment of thoracic cancers. Int J Mol Sci 21: 6024, 2020.

33. Maisano D, Mimmi S, Russo R, Fioravanti A, Fiume G, Vecchio E, Nistico N, Quinto I and Iaccino E: Uncovering the exosomes diversity: A window of opportunity for tumor progression monitoring. Pharmaceuticals (Basel) 13: 180, 2020.

34. Gerloff D, Lutzkendorf J, Moritz RKC, Wersig T, Mader K, Muller LP and Sunderkotter C: Melanoma-derived exosomal miR-125b-5p educates tumor associated macrophages (TAMs) by targeting lysosomal acid lipase A (LIPA). Cancers (Basel) 12: $464,2020$.

35. Wu M, Tan X, Liu P, Yang Y, Huang Y, Liu X, Meng X, Yu B, $\mathrm{Wu} \mathrm{Y}$ and Jin $\mathrm{H}$ : Role of exosomal microRNA-125b-5p in conferring the metastatic phenotype among pancreatic cancer cells with different potential of metastasis. Life Sci 255: 117857, 2020.

36. Drees EEE and Pegtel DM: Circulating miRNAs as biomarkers in aggressive B cell lymphomas. Trends Cancer 6: 910-923, 2020.

37. Yang W, Li Y, Li P and Wang L: PMA/IONO affects diffuse large B-cell lymphoma cell growth through upregulation of A20 expression. Oncol Rep 36: 1069-1075, 2016.

38. Aung T, Chapuy B, Vogel D, Wenzel D, Oppermann M, Lahmann M, Weinhage T, Menck K, Hupfeld T, Koch R, et al: Exosomal evasion of humoral immunotherapy in aggressive B-cell lymphoma modulated by ATP-binding cassette transporter A3. Proc Natl Acad Sci USA 108: 15336-15341, 2011.

39. Kato M, Sanada M, Kato I, Sato Y, Takita J, Takeuchi K, Niwa A, Chen Y, Nakazaki K, Nomoto J, et al: Frequent inactivation of A20 in B-cell lymphomas. Nature 459: 712-716, 2009.

40. Feng Y, Zhong M, Zeng S, Wang L, Liu P, Xiao X and Liu Y: Exosome-derived miRNAs as predictive biomarkers for diffuse large B-cell lymphoma chemotherapy resistance. Epigenomics 11: 35-51, 2019. 
41. Yuan WX, Gui YX, Na WN, Chao J and Yang X: Circulating microRNA-125b and microRNA-130a expression profiles predict chemoresistance to R-CHOP in diffuse large B-cell lymphoma patients. Oncol Lett 11: 423-432, 2016.

42. Kim SW, Ramasamy K, Bouamar H, Lin AP, Jiang D and Aguiar RC: MicroRNAs miR-125a and miR-125b constitutively activate the NF-kB pathway by targeting the tumor necrosis factor alpha-induced protein 3 (TNFAIP3, A20). Proc Natl Acad Sci USA 109: 7865-7870, 2012.

43. Li G, So AY, Sookram R, Wong S, Wang JK, Ouyang Y, He P, $\mathrm{Su}$ Y, Casellas R and Baltimore D: Epigenetic silencing of miR-125b is required for normal B-cell development. Blood 131: 1920-1930, 2018

44. Iida K, Fukushi J, Matsumoto Y, Oda Y, Takahashi Y, Fujiwara T, Fujiwara-Okada Y,Hatano M,NabashimaA,Kamura S and Iwamoto Y miR-125b develops chemoresistance in Ewing sarcoma/primitive neuroectodermal tumor. Cancer Cell Int 13: 21, 2013.
45. Zhao L, Liu W, Xiao J and Cao B: The role of exosomes and 'exosomal shuttle microRNA' in tumorigenesis and drug resistance. Cancer Lett 356: 339-346, 2015.

46. Oksvold MP, Kullmann A, Forfang L, Kierulf B, Li M, Brech A, Vlassov AV, Smeland EB, Neurauter A and Pedersen KW: Expression of B-cell surface antigens in subpopulations of exosomes released from B-cell lymphoma cells. Clin Ther 36: 847-862 e841, 2014.

(c) (i) $\Theta$ This work is licensed under a Creative Commons

EY No ND Attribution-NonCommercial-NoDerivatives 4.0 International (CC BY-NC-ND 4.0) License. 